\title{
Genome-wide identification and characterization of the Hsp70 gene family in allopolyploid rapeseed (Brassica napus L.) compared with its diploid progenitors
}

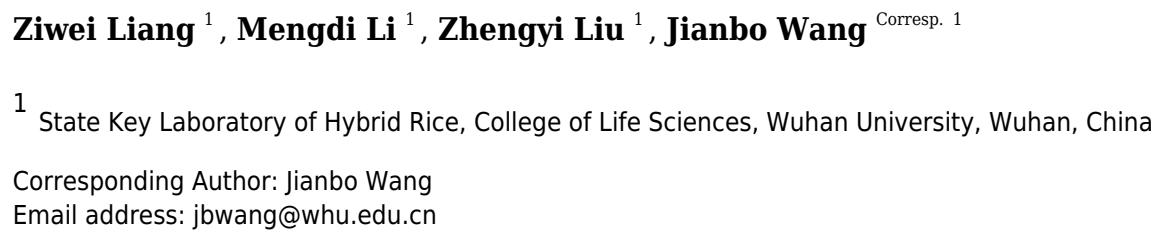

Heat shock protein 70 (Hsp70) plays an essential role in plant growth and development, as well as stress response. Rapeseed (Brassica napus L.) originated from recently interspecific hybridization between Brassica rapa and Brassica oleracea. In this study, a total of $47 \mathrm{Hsp70}$ genes were identified in $B$. napus $\left(A_{n} A_{n} C_{n} C_{n}\right.$ genome), including 22 genes from $A_{n}$ subgenome and 25 genes from $C_{n}$ subgenome. Meanwhile, 29 and $20 \mathrm{Hsp70}$ genes were explored in $B$. rapa $\left(A_{r} A_{r}\right.$ genome) and $B$. oleracea $\left(C_{0} C_{0}\right.$ genome), respectively. Based on phylogenetic analysis, $114 \mathrm{Hsp} 70$ proteins derived from $B$. napus, $B$. rapa, $B$. oleracea and Arabidopsis thaliana, were divided into 6 subfamilies containing $12 A_{r}-A_{n}$ and $13 C_{0}-C_{n}$ reliable orthologous pairs. The homology and synteny analysis indicated whole genome triplication and segmental duplication may be the major contributor for the expansion of Hsp70 gene family. Intron gain of BnHsp70 genes and domain loss of BnHsp70 proteins also were found in $B$. napus, associating with intron evolution and module evolution of proteins after allopolyploidization. In addition, transcriptional profiles analyses indicated that expression patterns of most BnHsp70 genes were tissue-specific. Moreover, Hsp70 orthologs exhibited different expression patterns in the same tissue and $C_{n}$ subgenome biased expression was observed in leaf. These findings contribute to exploration of the evolutionary adaptation of polyploidy and will facilitate further application of $\mathrm{BnHsp70}$ gene functions. 
2 Genome-wide identification and characterization of the

3 Hsp70 gene family in allopolyploid rapeseed (Brassica

4 napus L.) compared with its diploid progenitors

7 Ziwei Liang ${ }^{1}$, Mengdi Li ${ }^{1}$, Zhengyi Liu ${ }^{1}$, Jianbo Wang ${ }^{1}$

8

$9 \quad{ }^{1}$ State Key Laboratory of Hybrid Rice, College of Life Sciences, Wuhan University, Wuhan, 10 China

11

12 Corresponding Author:

13 Jianbo Wang ${ }^{1}$

14 Wuhan University, Wuhan, 430072, China

Email address: jbwang@whu.edu.cn 
18

19

20

21

22

23

24

25

26

27

28

29

30

31

32

33

34

35

36

37

38

39

40

41

42

43

44

45

46

47

48

49

50

51

52

53

54

55

56

57

\section{ABSTRACT}

Heat shock protein 70 (Hsp70) plays an essential role in plant growth and development, as well as stress response. Rapeseed (Brassica napus L.) originated from recently interspecific hybridization between Brassica rapa and Brassica oleracea. In this study, a total of $47 \mathrm{Hsp} 70$ genes were identified in $B$. napus $\left(\mathrm{A}_{n} \mathrm{~A}_{\mathrm{n}} \mathrm{C}_{\mathrm{n}} \mathrm{C}_{\mathrm{n}}\right.$ genome), including 22 genes from $\mathrm{A}_{\mathrm{n}}$ subgenome and 25 genes from $\mathrm{C}_{\mathrm{n}}$ subgenome. Meanwhile, 29 and $20 \mathrm{Hsp} 70$ genes were explored in $\mathrm{B}$. rapa ( $\mathrm{A}_{\mathrm{r}} \mathrm{A}_{\mathrm{r}}$ genome) and $B$. oleracea $\left(\mathrm{C}_{\mathrm{o}} \mathrm{C}_{\mathrm{o}}\right.$ genome $)$, respectively. Based on phylogenetic analysis, 114 Hsp70 proteins derived from B. napus, B. rapa, B. oleracea and Arabidopsis thaliana, were divided into 6 subfamilies containing $16 \mathrm{~A}_{\mathrm{r}}-\mathrm{A}_{\mathrm{n}}$ and $11 \mathrm{C}_{\mathrm{o}}-\mathrm{C}_{\mathrm{n}}$ reliable orthologous pairs. The homology and synteny analysis indicated whole genome triplication and segmental duplication may be the major contributor for the expansion of $H s p 70$ gene family. Intron gain of $\mathrm{BnHsp} 70$ genes and domain loss of BnHsp70 proteins also were found in B. napus, associating with intron evolution and module evolution of proteins after allopolyploidization. In addition, transcriptional profiles analyses indicated that expression patterns of most BnHsp70 genes were tissue-specific. Moreover, Hsp 70 orthologs exhibited different expression patterns in the same tissue and $\mathrm{C}_{\mathrm{n}}$ subgenome biased expression was observed in leaf. These findings contribute to exploration of the evolutionary adaptation of polyploidy and will facilitate further application of $B n H s p 70$ gene functions.

\section{INTRODUCTION}

Taken as a whole, polyploidization has long been seen as a key force in the evolution of eukaryotic nuclear genomes, and about $70 \%$ of angiosperms have experienced relatively recent genome doubling in the form of polyploidy (Masterson, 1994). Polyploidy often shows morphological innovation, can provide the basic material for the origin of plant adaptation, and thus have a significant impact on plant species diversity (Adams \& Wendel, 2005). As the most common type of polyploidy, allopolyploidy generated from hybridization of two formerly differentiated genomes usually from different species. The whole process of allopolyploidization event involves a series of molecular and physiological adjustments. The onset of genomic shock occurred accompanied by the merger of two distinct genomes reunited in a common nucleus (McClintock, 1984). This collision among the subgenomes sometimes leads to subgenome bias and even to the dominance of one of a subgenome, thus affecting homologous exch $_{\text {anges, }}$, epigenetic regulation and gene expression (Bird et al., 2018). Meanwhile, some duplicate gene pairs (homologs) with similar or redundant functions are retained nonrandomly. Recent insights into subgenome bias and duplicate gene retention in polyploids contribute to sharpen researches of polyploid adaptation and provide great opportunities for trait improvement of polyploid species in agriculture (Samans, Chalhoub \& Snowdon, 2017; Bird et al., 2018).

$B$. napus $(2 \mathrm{n}=4 \mathrm{x}=38)$, an allotetraploid species, arose from gene duplication after natural hybridization between the diploid ancestors of $B$. rapa $(2 \mathrm{n}=2 \mathrm{x}=20)$ and B. oleracea $(2 \mathrm{n}=3 \mathrm{x}=18)$, followed by spontaneous chromosome doubling (Chalhoub et al., 2014). Compared to Arabidopsis, the genomes of all Brassica species have experienced a lineage-specific whole 
58

59

60

61

62

63

64

65

66

67

68

69

70

71

72

73

74

75

76

77

78

79

80

81

82

83

84

85

86

87

88

89

90

91

92

93

94

95

96

97

genome triplication (WGT) event, and rediploidization would follow that involved substantial genomic shock including gene loss and exchanges between genomes. With beneficial heterosis effect, $B$. napus has better adaptability to natural environment and can produce desirable traits in the agricultural environment. To date, B. napus is the third largest oilseed crops all over the world, with wide planting area and large yield. It is believed that polyploid lineages may have complex relationships with their diploid ancestors. B. rapa with 530 Megabase (Mb), B. oleracea with $630 \mathrm{Mb}$ and $B$. napus with $849.7 \mathrm{Mb}$ genomes have been released recently, which often used to elucidate genome evolution in angiosperms (Chalhoub et al., 2014). Also, the $H s p 70$ gene family is well conserved in the evolution of angiosperms. Accordingly, it provides new chance to understand the origin and evolution of the $H s p 70$ gene family in Brassica genomes.

Hsp70s, approximately 70kiloDalton $(\mathrm{kDa})$ in size, are the most conserved and ubiquitous in heat shock proteins (HSPs) which are of great significance responsive to heat stress reaction (HSR) of plants (Lindquist, 1986; Feder \& Hofmann, 1999). They function as molecular chaperones to prevent protein aggregation, deformation and promote protein refolding to repair damaged protein (Wang et al., 2004; Mayer \& Bukau, 2005). Structurally, all Hsp70s have two major functional domains: highly conserved nucleotide-binding domain (NBD) and substratebinding domain (SBD) that covered variable C-terminal 'lid' (Lindquist, 1986; Zhu et al., 1996). Despite the acidic SBD $\beta$ insertion and longer C-terminal extension in Hsp110s, they share the same domain composition as classical Hsp70 and are therefore considered to be component of the Hsp70 family (Liu \& Hendrickson, 2007). The Hsp 70 gene family has been widely reported in many plants, e.g., A. thaliana (18 genes); rice (32 genes); soybean (61 genes) and pepper (21 genes) (Lin et al., 2001; Sarkar, Kundnani \& Grover, 2013; Zhang et al., 2015; Guo et al., 2016). Hsp70s have been confirmed to be indispensable in plant development, as well as associate with plant stress resistance. AtHsp 70-15-deficient led to Arabidopsis plant dwarfing, leaf malformation and growth retardation (Jungkunz et al., 2011). Double-knockout mutations in cpHsc70-1 (At4g24280) and cpHsc70-2 (At5g49910) were defective to both female and male gametes $(S u \& L i, 2008)$. In resistance to abiotic stresses, cytosolic/nuclear Hsp70s in $A$. thaliana had both specific and redundant functions (Leng et al., 2017). Expression of $H s p 70$ was strongly correlated with thermotolerance in rice and can be considered potential biomarker in future rice breeding programs (Ali et al., 2017).Until now, little is known about the $H s p 70$ gene family in Brassica species.

In this study, detailed studies of the $H s p 70$ gene family of $B$. napus and diploid parental species were carried out. All of the putative $H s p 70$ orthologous gene members in B. napus and diploid parental genomes were firmly identified using sequence similarity and Hsp70 specific domain. A comparative phylogenetic analysis was performed to infer the evolutionary relationships of the Hsp70 homologs of B. napus and its relatives, including A. thaliana, B. rapa and B. oleracea. Synteny and duplicated gene analysis among B. rapa, B. oleracea and B. napus genomes were investigated for better understanding the expansion patterns and evolution forces of the $H s p 70$ gene family. We also explored $H s p 70$ gene expression patterns in four tissues (stem, leaf, flower and silique). These thorough analyses of the $H s p 70$ gene family in allopolyploid $B$. 
98

99

100

101

102

103

104

105

106

107

108

109

110

111

112

113

114

115

116

117

118

119

120

121

122

123

124

125

126

127

128

129

130

131

132

133

134

135

136

137

napus species and two diploid ancestors will help to better understand the molecular events after polyploidization, and will also open up more possibilities for further studies of B. napus and other polyploid species.

\section{MATERIALS \& METHODS Identification of $\mathrm{Hsp70}$ gene members}

In order to identify $H s p 70$ gene members in the B. napus (cv. Darmor-bzh), B. rapa (cv. chiifu401-42) and B. oleracea (var. capitata line 02-12), all proteins of B. napus, B. rapa and B. oleracea in the Brassica database (BRAD: http://Brassicadb.org/brad/) (Cheng et al., 2011) were performed Protein Basic Local Alignment Search Tool (BLASTp) algorithms using 18 Hsp70 protein sequences of Arabidopsis downloaded from the Arabidopsis Information Resource (TAIR10: https://www.Arabidopsis.org/) (Lamesch et al., 2012). The maximum E-value was $>1 \mathrm{e}-5$. Meanwhile, the Hidden Markov Model (HMM) profile of Hsp70 seed file (PF00012) was obtained from the Pfam database (http://pfam.sanger.ac.uk/search/) (Finn et al., 2016) and then submitted to search in HMMER (http://hmmer.org/) (Eddy, 2009) software locally. Proteins with Hsp70 domain were extracted from BRAD. Integrating the results of two methods, all redundant sequences were removed manually. The candidate sequences were further confirmed by the following databases: NCBI Conserved Domain Search database (CDD: http://www.ncbi.nlm.nih.gov/Structure/cdd/wrpsb.cgi/) (Marchler-Bauer et al., 2015), Simple Module Architecture Research Tool (SMART) database (http://smart.embl-heidelberg.de/) (Letunic et al., 2004) and InterProScan database (http://www.ebi.ac.uk/interpro/) (Mitchell et al., 2015). Finally, all identified genes encoding corresponding proteins were designated taking reference to Arabidopsis nomenclature (Lin et al., 2001).

All genome information of three species were downloaded from BRAD, including chromosome distribution, protein sequences and genomic sequences containing full coding sequences (CDS). The molecular weight (Mw) and theoretical isoelectric point (pI) of each Hsp70 protein were analyzed using the 'compute $\mathrm{pI} / \mathrm{Mw}$ ' tool of Expert Protein Analysis System (ExPASy: https://web.expasy.org/tools/) (Wilkins et al., 1999). The predicted value of the grand average of hydropathy (GRAVY) and instability index were calculated by ExPASy. All Hsp70 protein sequences of $B$. napus, B. rapa and B. oleracea were analyzed using the Protein Subcellular Localization Prediction (WoLF PSORT: http://www.genscript.com/psort/wolf psort.html/) (Horton et al., 2007) online tools in order to predict subcellular localization.

\section{Prediction of cis-acting elements in $\mathbf{H s p 7 0}$ gene promoters}

Approximately $1500 \mathrm{bp}$ upstream sequences of the translation initiation site (ATG) were extracted from BRAD and investigated using Plant Cis-Acting Regulatory Element (PlantCARE: http://bioinformatics.psb.ugent.be/webtools/plantcare/html/) (Lescot et al., 2002), which were to determine putative $c i s$-acting regulatory elements in the promoter region of $H s p 70$ genes. 
138 Comparative phylogenetic analysis of Hsp70 proteins

139 Sequence alignments were performed and phylogenetic analyses were constructed to explore the

140

141

142

143

144

145

146

147

148

149

150

151

152

153

154

155

156

157

158

159

160

161

162

163

164

165

166

167

168

169

170

171

172

173

174

175

176

177 evolutionary relationship of Hsp70s in B. napus, B. rapa, B. oleracea and A. thaliana. All protein sequences were performed multiple alignments in MUSCLE program of Molecular Evolutionary Genetics Analysis (MEGA 7) software (Kumar, Stecher \& Tamura, 2016). An unrooted phylogenetic tree was constructed based on the Maximum Likelihood (ML) method, with a 1000 bootstrap replicates and a Jones-Taylor-Thornton (JTT) model. The Interactive Tree of Life (iTOL: http://itol.embl.de/) (Letunic \& Bork, 2016) website was used to better visualize the tree.

\section{Analysis of Hsp70 gene structures and conserved domains of their encoding proteins}

Using FASTA files of the coding and corresponding genomic sequences, exon-intron structures of $H s p 70$ gene were determined with the Gene Structure Display Server （GSDS: http:/ /gsds.cbi.pku.edu.cn/) (Hu et al., 2015). The conserved motifs of Hsp70 protein were investigated with the Multiple EM for Motif Elicitation (MEME: http://meme-suite.org/) (Bailey et al., 2009) tool, with parameters set as follows: minimum motif width: 6, maximum motif width: 50, and maximum number of motifs: 20 ; default values were used for remaining parameters. To find conserved signature domain of $\mathrm{Hsp} 70$ proteins, sequence alignment of all identified Hsp70 proteins were carried out using Multiple alignment program for amino acid or nucleotide sequences (MAFFT: http://mafft.cbrc.jp/alignment/software/) (Katoh, Rozewicki \& Yamada, 2017), and were displayed by Jalview software (Waterhouse et al., 2009).

\section{Chromosome localization and $\boldsymbol{H s p} 70$ gene duplication events}

The position and length of $H s p 70$ genes in each chromosome extracted from BRAD, then all Hsp70 genes were mapped to specific chromosomes except some genes located on random scaffolds. MapInspect tool was used to show the location information (Wang et al., 2019). Duplicated $H s p 70$ genes were detected using Nucleotide BLAST (BLASTn) searched against protein-coding genes and their paralogs, and complied to the following criteria: the alignable coding nucleotide sequence was covered $80 \%$ of the longer gene, as well as the identity of the alignable sequences was $>80 \%$ (Yang et al., 2008; Zhou et al., 2004). If the physical distance of two homologous genes was $<50$ Kilobase $(\mathrm{kb})$, it was defined as tandemly duplicated genes (Cannon et al., 2004).

To investigate synteny relationship of closely related species, all $H s p 70$ genes among $B$. napus, B. rapa, B. oleracea and $A$. thaliana were evaluated by searching "syntenic genes" in BRAD. The orthologous $H s p 70$ genes located on syntenic chromosome blocks were displayed using Circos software (Krzywinski et al., 2009).

For estimation of selection mode for $B n H s p 70, B r H s p 70$ and $B o H s p 70$ genes, the ratio of nonsynonymous to synonymous substitutions $(\mathrm{Ka} / \mathrm{Ks})$ of all segmental gene pairs were calculated by DnaSP (Librado \& Rozas, 2009). The value of $\mathrm{Ka} / \mathrm{Ks}$ ratio $>1,=1$ and $<1$ are represented for positive selection, neutral selection and negative or stabilizing selection, respectively. 


\section{Plant material and tissue collection}

180

181

182

183

184

185

186

187

188

189

190

191

192

193

194

195

196

197

198

199

200

201

202

203

204

205

206

207

208

209

210

211

212

213

214

215

216

In this study, healthy seeds of B. napus (cv. Darmor), B. rapa (cv. chiifu) and B. oleracea (cv. Jinzaosheng) were selected for further cultivation. In the autumn of 2017, all seedlings were grown in natural environments of Wuhan University. According to the $\mathrm{BBCH}$ (the Biologische Bundesanstalt, Bundessortenamt and Chemical industry) scale of winter oilseed rape (B. napus), four tissues with the flowering phase (60-69) that included inflorescence stems, young leaves, flowers and siliques from 6-month-old plants of 10 days after pollination(DAP), were collected in the spring of 2018 (Habekotte, 1997; Boettcher et al., 2016). They were frozen in liquid nitrogen and stored at $-80{ }^{\circ} \mathrm{C}$. Three biological replicates of all samples were performed in this experiment.

\section{Analysis of $\boldsymbol{H s p 7 0}$ gene expression patterns in various tissues}

To analyze $H s p 70$ gene expression patterns of different tissues in B. napus and two diploid progenitors, the row RNA-seq reads were deposited in the NCBI database (accession number SRR7816633-SRR7816668) (Li et al., 2019). RNA extraction and RNA-seq approach were similar to a previous study (Wang et al., 2019). Fragments Per Kilobase of transcript per Million mapped reads (FPKM) values was calculated by RSEM (Expectation-Maximization) tool to estimate the gene expression levels ( $L i \&$ Dewey, 2011). The specific formula is as follows:

$\mathrm{FPKM}=\frac{10^{6} \mathrm{C}}{\mathrm{NL} / 10^{3}}$, where $\mathrm{C}$ in the numerator represents the number of fragments mapped only to the gene, and $\mathrm{N}$ and $\mathrm{L}$ in the denominator respectively represent the total number of fragments mapped only to the reference genome and the number of bases in the coding region of the gene. The data were normalized in order to more intuitively compare the differences of the same gene in different samples. Heat maps were generated with Heat map Illustrator (HemI: http://hemi.biocuckoo.org/down.php/) (Deng et al., 2014).

\section{RESULTS}

\section{Genome-wide identification of $\mathrm{Hsp} 70$ genes in tetraploid B. napus and diploid $B$. rapa and $B$. oleracea}

To systematically explore all of the $H s p 70$ gene family members, 107,39 and 33 non-redundant putative protein sequences of $B$. napus, $B$. rapa and B. oleracea were initially retrieved by BLASTn program in BRAD. Additional 1, 1 and 9 proteins of three Brassica species were also retrieved by HMM-based search with Hsp70 domain. A total of 61, 11 and 22 sequences of $B$. napus, B. rapa and B. oleracea were discarded for lack of Hsp70-specific function domain. Eventually, 47, 29 and $20 H s p 70$ genes encoding corresponding proteins were identified in the $B$. napus and two progenitors, B. rapa and B. oleracea genomes (Table 1; Table S1). All Hsp70 genes (eg. BnA.Hsp 70-12e, BrHsp70-2a and BoHsp 70-5b) were designated corresponding to their orthologs of Hsp 70 genes in A. thaliana (AtHsp 70), where the last letter in the naming was "a" meaning the highest homology with Arabidopsis, next by "b", and so on. And the capital 
217 letter $\mathrm{A}$ or $\mathrm{C}$ in the name of $B$. napus took reference to the subgenome $\mathrm{A}_{\mathrm{n}}$ or $\mathrm{C}_{\mathrm{n}}$ location. Hsp70218 15s to Hsp70-17s of B. napus and two progenitors all classified as Hsp110s, because they had 219 Hsp70 specific domains and their size are much larger than that of classic Hsp70s. Annotation 220 information of all identified Hsp70 proteins were shown in Table S2. There were no orthologous $221 H s p 70$ genes for AtHsp70-1, -3, -18 and -14 which were found in B. napus and two parental 222 genomes. Additionally, no orthologous gene for AtHsp 70-7 and AtHsp 70-6 were found in B. 223 rapa genome and B. oleracea genome, respectively. AtHsp70-2 had only one homolog 224 (BnC.Hsp70-2) in B. napus genome, while BrHsp70-2s contained 6 members and BoHsp70-2s 225 contained 4 members homologous to AtHsp70-2. The difference of the number of copies 226 between B. napus and diploid progenitors might suggest a large gene loss event occurred in the 227 Hsp70 gene family during polyploidization.

228 The length of BnHsp70s ranged from 498 to 956 amino acids (aa), with the molecular weights

229

230 varing between $54.70 \mathrm{kDa}$ to $106.32 \mathrm{kDa}$ (Table S3). The GRAVY value of all BnHsp70s except for BnHsp70-8s was negative, indicating that most of BnHsp70 proteins were hydrophilic and suggesting BnHsp70s possibly involved in tolerance to drought stress (Beck et al., 2007).

233 Approximately $74.5 \%(35 / 47)$ of BnHsp70 proteins (cutoff $<40$ ) had stable structures in a test tube and the $\mathrm{pI}$ value of all proteins except for except for BnC.Hsp70-6d (pI =8.98) had low isoelectric points ( $\mathrm{pI}<7$ ). The WoLF PSORT were used to predict the subcellular location of 47 BnHsp70 proteins; The result showed BnHsp70s were mainly localized on cytoplasm (20),

236 followed by ER(10), then mitochondrion (7) and chloroplast (7), and 3 were predicted to located

237 on other cellular compartments. Meanwhile, BrHsp70s and BoHsp70s of cytoplasm-localized had the largest proportion, each with 13 genes (Table S4). In B. rapa genome, Hsp70 proteins of ER-localized, mitochondrion-localized and chloroplast-localized were predicted that had 4, 4 and 5 members, respectively (Table S4). In B. oleracea genome, Hsp70 proteins of ER-localized, mitochondrion-localized and chloroplast-localized were predicted that had 3, 2 and 1 members, respectively (Table S4). Further, these results showed subcellular locations of BnHsp70s were basically consistent with that of the corresponding homologs in two diploid progenitors (Table S4).

245

246

247

Phylogenetic analyses of Hsp70 proteins in Arabidopsis and three Brassica species

249 An unrooted phylogenetic tree was built using the alignment of a total of $114 \mathrm{Hsp} 70$ amino acid sequences, which included 47 members from B. napus, 29 from B. rapa, 20 from B. oleracea and 18 from A. thaliana in present study. By the topology of the ML tree and bootstrap analysis of 1000 replicates, all Hsp70 proteins were clearly divided into six subfamilies (named subfamily A to F) in final results (Fig. 1). Subfamily A was the largest subfamily containing 32 members, while subfamily $\mathrm{E}$ had only 5 members which were likely to be truncated based on $A$. thaliana orthologs (Lin et al., 2001; Sun et al., 2001). A total of 24 members of subfamily F were all 255 256 Hsp110/SSE subfamily members which were structurally very similar to Hsp70. Subfamily B was comprised of 15 members, subfamily $\mathrm{C}$ consisted of 17 members and subfamily D contained 
257

258

259

260

261

262

263

264

265

266

267

268

269

270

271

272

273

274

275

276

277

278

279

280

281

282

283

284

285

286

287

288

289

290

291

292

293

294

295

296

21 members. Analysis of localization prediction ascertained that Hsp70 proteins encoded by genes of subfamily A and D were located in the cytoplasm and ER. Mitochondrial and chloroplastic $H s p 70$ genes clustered on subfamily C and B, respectively (Fig. 1; Table S4).

In addition, Hsp70s of $A$. thaliana distributed in all subfamilies, which also indicated all BnHsp70 genes had orthologs in A. thaliana genome. The AtHsp70s for each subfamily except subfamily E matched multiple sets of orthologs from B. napus and two progenitors. Generally, the higher of bootstrap values within each subfamily, the more statistically reliable of the derivatively homologous pairs that were branched at the same final level. A reliable pair indicates two genes had the closest relatives which located in the end of the same branch and had high bootstrap values (> 50\%) in a phylogenetic tree. Within this tree, a total of 37 reliable homologous $H s p 70$ gene pairs were observed, and most of them were orthologous pairs between $A_{n}$ and $C_{n}$ subgenomes of B. napus and their respective parental genomes, with $16 A_{\mathrm{r}}-A_{n}$ pairs and $11 \mathrm{C}_{0}-\mathrm{C}_{\mathrm{n}}$ pairs. These results supported to the gene duplication events in B. napus genome and indicated $H s p 70$ orthologous genes of distinct subfamilies kept highly conserved in respective genome.

\section{Structure of Hsp70 genes and conserved domain of Hsp70 proteins in three Brassica species}

To better characterize the structural conservation and diversification of $B n H s p 70$ genes during their evolution, the exon-intron organization of individual $B n H s p 70$ gene in coding sequence was obtained according subfamily membership. The number of introns varied greatly, and the arrangement of introns was complex in whole $H s p 70$ gene family. The numbers of introns in total genes ranged from 0 to 14 (Fig. 2B). In Hsp110/SSE subfamilies, all genes had multiple introns and the highest number of intron was found in BnC.Hsp 70-15d. The 4 truncated genes of subfamily E had no intron, whether they were members among $B$. napus or its diploid progenitors. Genes of subfamily A had zero or one intron except for BnC.Hsp70-2. These results suggested the gene structure within a single subfamily was highly conserved. In the course of comparison of exon-intron structure of $B n H s p 70$ s and two progenitor species, 25 reliable orthologous pairs were analyzed, which had high bootstrap values in a phylogenetic relationship. Approximately $40.0 \%$ (10/25) genes in B. napus had an identical intron number and intron phase corresponding to orthologous genes in B. rapa and B. oleracea (Figs. 2A and 2B). Other 7

$B n H s p 70$ genes corresponding to their ancestral genes exhibited exon-intron loss/gain variations, and 3 genes changed their intron phase after allopolyploidy, while obvious differences were observed in exon lengths of $5 \mathrm{BnHsp} 70$ genes. Overall, intron numbers or phases were similar among genes with higher genetic and evolutionary similarities.

Like other identified species, the multiple protein sequence alignment of BnHsp70 family members revealed two major domains known. The highly conserved N-terminal ATPase domain contained three typical signature sequences, which were contained in approximately 400 aa (Fig. S1). Intriguingly, although the C-terminal domain was highly variable, it's exclusive and highly preserved C-terminus motif can be used to distinguish proteins of some different subfamilies. All 
297

298

299

300

301

302

303

304

305

306

307

308

309

310

311

312

313

314

315

316

317

318

319

320

321

322

323

324

325

326

327

328

329

330

331

332

333

334

335

336

Hsp70 proteins of cytoplasm-localized possessed signal EEVD sequence at the C-terminus. The sequences for $72.20 \%$ (13/18) ER Hsp70s and 69.20\% (9/13) chloroplast Hsp70s had the conserved sequence HDEL and DVIDADFTDSK in the C-terminus, respectively (Fig. S1). However, the retention signal motif for mitochondrion Hsp70s, GDAWV and SPSQ (I/V) G, was observed in the N-terminal ATPase domain. These results suggested that the Hsp70 family was relatively conserved, while some motif sequences changed slightly during Brassica evolution, which possibly contributed to extended special biological function.

Using MEME, a total of 20 conserved motifs was recognized, with lengths ranging from 11 to 50 aa (Table S5; Fig. 2C). Motif 6, 4 and 5 were found in $81.3 \%, 89.6 \%$ and $94.8 \%$ Hsp70 proteins, whose conserved region contained conserved N-terminal domain. Three motifs created from MEME analysis results represented conserved signature sequences of Hsp70 protein specific-domain. Motif 6 contained GIDLGTT (N/Y) SCV sequences, motif 4 contained DLGGGTFDVS sequences and LVGG (S) TR (I) PKVQ sequences was included in motif 5 (Fig. $2 \mathrm{C}$; Fig. S2). However, some proteins in distinct subfamily possessed preservation and expansion of specific motifs for distinguishable from those in other subfamilies. For instance, motifs 16 and 20 were uniquely found in all members of Hsp110/SSE subfamily, whereas motif 3 was absent only in this subfamily. Besides BrHsp70-2e, motif 11 was found in all members from subfamily A and D. Hsp70 members in subfamily E which were less similar to other subfamilies, contained the identical and lowest number of motifs only nine (Fig. 2C).

Furthermore, 17 out of 25 orthologs in B. napus had a similar domain composition, which was identical to the parental progenitors. But it seems that some BnHsp70 orthologs had truncated motifs during the allopolyploidy process, such as BnC.Hsp70-5c and BnC.Hsp70-5d lost their motif 6 . These results imply that motifs containing the Hsp70-specific domains are highly conserved in all members and the type, order and number of motifs may also be used to classify different proteins for functional differences.

\section{Chromosomal distribution and duplication pattern analysis of $H s p 70$ genes in three Brassica species}

The chromosomal location of all Hsp 70 genes in the three Brassica species was investigated based on the physical position of whole genes and was shown in Fig. 3. A total of 42 BnHsp70s correctly mapped onto different chromosomes, excluding 5 genes located on the random scaffold of the 'Darmor- $b z h$ ' reference sequences. BnHsp70 genes were clearly distributed across 16 of the 19, except for chromosome $\mathrm{A}_{n} 05, \mathrm{~A}_{n} 10$, and $\mathrm{C}_{\mathrm{n}} 09$ (Fig. 3C; Table 1). The number of Hsp70 genes varied considerably among different chromosome. Chromosome $\mathrm{C}_{\mathrm{n}} 01$ in B. napus carried the greatest gene numbers (6) and it is worth mentioning that BnC.Hsp70-6a, $-6 c$ and $-6 d$ in $\mathrm{C}_{\mathrm{n}}$ 01 were clustered in a sequence distance of $50 \mathrm{~kb}$. Moreover, $42 \mathrm{BnHsp} 70 \mathrm{~s}$ had non-random distribution across 16 chromosomes, with 20 in the $A_{n}$ subgenome and 22 in the $C_{n}$ subgenome. The number of $H s p 70$ genes had approximately equal distribution on the $A_{n}$ and $C_{n}$ subgenome. Furthermore, distribution of BnHsp70 genes appeared to a consistent match with that of their orthologous genes in diploid ancestor genomes ( $A_{r}$ genome, 29 and $C_{o}$ genome, 17). The 
337

338

339

340

341

342

343

344

345

346

347

348

349

350

351

352

353

354

355

356

357

358

359

360

361

362

363

364

365

366

367

368

369

370

371

372

373

374

375

376

distribution of $18 \mathrm{BnHsp} 70$ genes in $\mathrm{A}_{\mathrm{n}}$ subgenome was identical to orthologous gene in $\mathrm{B}$. rapa genomes, while 11 of $\mathrm{C}_{\mathrm{n}}$ subgenome were identical to that in $B$. oleracea genome (Fig. 3). These results indicated chromosome location of $H s p 70 \mathrm{~s}$ might be derived from long-term gene duplication in the evolution process.

In order to better understanding $H s p 70$ gene expansion and clustering, it is important to analyze chromosomal syntenic gene in Brassica species and A. thaliana. Generally, synteny analysis represented genomic fragments from different species that derived from an identical ancestor, which mainly was used to share gene annotations and reveal genomic evolution of related species (Cheng et al., 2012). By searching 'syntenic gene' in BRAD, a total of 63 Hsp70 genes in three Brassica species showed conserved synteny with those in $A$. thaliana and were positioned in the same conserved chromosomal blocks, such as A, U, R, F, S, J and D (Schranz, Lysak \& Mitchell-Olds, 2006). In addition, syntenic genes in three Brassica species were divided into three fractionated subgenomes (Liu et al., 2014). LF (Least-fractionated) subgenome contained $23 \mathrm{Hsp} 70$ genes, and both 20 genes were caught in MF1 (Medium-fractionated) and MF2 (Most-fractionated) subgenome (Table S6). About 65.6\% (63/96) of Hsp70 genes from three Brassica species was located in syntenic blocks, suggesting the expansion of $H s p 70$ genes was also accompanied by gene loss. To detect the retention or loss of Hsp70 genes after WGT and allopolyploidy events, the synteny relationship of $H s p 70$ gene homologs were further visually depicted by Circos software between $\mathrm{A}_{\mathrm{n}}$ and $\mathrm{C}_{\mathrm{n}}$ subgenome of B.napus and two diploid progenitors, B. rapa and B. oleracea. (Fig. 4; Table S6). A total of 13 AtHsp 70 genes retained corresponding syntenic paralogs in Brassica species. In these genes, four Hsp70 genes (Hsp704/5/9/13) among all three Brassica species were completely preserved in the same block of synteny, whose function might be enhanced adaptation of $B$. napus in an adverse environment. Interestingly, 2 of 4 AtHsp70 genes (AtHsp70-5/9) were preserved as two copies among B. rapa and $B$. oleracea genomes and $\mathrm{A}_{\mathrm{n}}$ and $\mathrm{C}_{\mathrm{n}}$ subgenome, which were located on symmetrical subgenome (LF, MF1 or MF2). Only AtHsp70-6 were retained as all three copies in B. rapa genome after triplication and maintained synteny with BnHsp70-6s, which might imply these genes had a unique biological function during evolution. Notably, synteny analyses implied BnC.Hsp70-6a/6c/6d genes might have presented tandem array, which was consistent with the chromosomal location of these genes (Table S6; Fig. 3).

Moreover, the generation and maintenance of multigene family may be significantly affected by tandem duplication and segmental duplication (Cannon et al., 2004). According to the descriptions (Zhou et al., 2004), those closely related genes with a physical sequence of $50 \mathrm{~kb}$ were defined as tandem duplication. It was discussed that the fate of orthologous $H s p 70$ gene pairs in the tandem array of Brassica lineages split from Arabidopsis. Only one tandem BnHsp70 gene cluster was identified in B. napus genome, which was composed of BnC.Hsp70-6a, BnC.Hsp70-6c and BnC.Hsp70-6d. But there were two tandem duplicates in B. rapa genomes, BrHsp70-2a/2f and BrHsp70-6b/6d (Fig. 3A). The previous study showed that four genes (AtHsp70-1/2 and AtHsp70-14/15) were considered as tandem duplicated genes out of 18 Hsp70 genes (Lin et al., 2001). Two-gene tandem array (BrHsp70-2a/2f) in B. rapa had an ancient copy 
377 but have not retained in B. napus, which presumed those two tandem genes arose before the 378 divergence of $A$. thaliana and Brassica ancestor but was lost during allopolyploidization. 379 Another two-gene tandem array in B. rapa, BrHsp70-6b/6d, were considered as species-specific 380 tandem duplications which may be formed by environmental selection pressures after Brassica 381 speciation. They had retained their copies in B. napus, while the corresponding three-gene 382 tandem array in B. napus located on chromosome $\mathrm{C}_{\mathrm{n}}$ 01. According to analysis, 46 BnHsp70

383

384

385

386

387

388

389

390

391

392

393

394

395

396

397

398

399

400

401

402

403

404

405

406

407

408

409

410

411

412

413

414

415

416 genes was thought of as segmentally duplicated genes allowing the criteria described above, which were much higher than 25 and 15 duplicate genes detected in $\mathrm{BrHsp} 70 \mathrm{~s}$ and $\mathrm{BoHsp} 70 \mathrm{~s}$, respectively. It can be concluded that segmental duplication events play a greater crucial role than tandem duplication during the expansion of Hsp70 genes in B. napus.

Typically, the non-synonymous (Ka or $\mathrm{dN}$ ) and synonymous (Ks of $\mathrm{dS}$ ) substitution ratios were calculated to verify whether selective pressures acted on these segmental duplications. The results revealed the $\mathrm{Ka} / \mathrm{Ks}$ values of all identified $H s p 70$ segmental duplications were always lower than 1, indicating a purifying selection on these duplicates (Table S7). In general, the $\mathrm{Ka} / \mathrm{Ks}$ values significantly lower than 0.1 suggested strong purifying selection stress and functional constraint of duplicated genes. Approximately $77.01 \%$ of $\mathrm{BnHsp} 70$ segmentally duplicated genes had a $\mathrm{Ka} / \mathrm{Ks}$ value less than 0.1 , making the structures of these gene pairs may tend to conservation and functions tend toward similarity.

\section{Cis-acting elements of the Hsp70 gene promoter in three Brassica species}

To evaluate the potential transcriptional regulation of different cis-acting elements distributed in the promoters of $B n H s p 70$ genes, promoter sequences within $1500 \mathrm{bp}$ upstream of three Brassica species were investigated and cis-acting regulatory elements (CAREs) in these regions were explored by PlantCARE database. Mainly seventeen types of defence-related CAREs were detected in the promoters of BnHsp70s: hormone responsive elements (10) and environmental stress related elements (7). As showed in Table S8, the promoter regions of all $\mathrm{BnHsp} 70$ members contained 1-6 hormone-related elements and 2-6 stress-related elements. ARE, essential for the anaerobic induction, was detected in 44 of $47 \mathrm{BnHsp} 70$ genes except BnC.Hsp70-9a, BnC.Hsp70-15d and BnC.Hsp70-17c. HSE-elements were detected in 26 $B n H s p 70$ promoter regions, and the highest number (5) was found on BnA.Hsp 70-4c. Additionally, some CAREs such as MBS, TC-rich repeats and CGTCA-motif were also presented in 39, 39 and 33 promoter regions of BnHsp70 genes, respectively (Table S8). Moreover, the promoter regions of 14 BnHsp 70 genes contained more CAREs than their orthologous genes when compared 25 of reliable orthologous $H s p 70$ gene pairs. Also, four orthologous pairs (BrHsp70-13/BnA.Hsp70-13a, BoHsp70-13/BnC.Hsp70-13b, BrHsp7016/BnA.Hsp70-16b and BoHsp7-16/BnC.Hsp70-16a) had the same type and number of CAREs. These analyses suggested that cis-elements of some $B n H s p 70$ genes were relatively conserved after polyploidization, and expression regulations of most $B n H s p 70$ genes should be more abundant in response to different stress compared with diploid progenitors. 
417 Expression patterns of $\boldsymbol{H s p} \mathbf{7 0}$ genes in different tissues of three Brassica 418 species

419 Since $H s p 70$ members participate in diverse cellular functions during normal plant growth and 420 under abiotic stress conditions, RNA-seq data of stem, leaf, flower and silique in $47 \mathrm{BnHsp} 70$ 421 genes were extracted (Table S9). A heat map was constructed among the examined tissues to 422 display diverse expression levels (Fig. 5C). It is worth to mention that all $H s p 70$ genes in this 423 research except $B n C . H s p 70-6 d$ and BrHsp 70-6d produced relevant gene expression data.

424 BnC.Hsp 70-6d and BrHsp70-6d lacked expression data in all samples of four tissues, illustrating 425 that it might be a non-functional expression or have special temporal and spatial expression patterns but not be detected in this study. The heat map analysis indicated that expression of $B n H s p 70$ members varied greatly among tissues, holding functional diversification of the $H s p 70$ genes during B. napus development. As showed in Fig. 5C, the majority of BnHsp 70 genes exhibited significantly tissue-specific expression patterns in all examined tissues. 6 BnHsp $70 \mathrm{~s}$ in leaf, 3 in stem (BnA.Hsp70-11a/15a and BnC.Hsp70-15c) and 1 in silique (BnA.Hsp70-10b) showed relatively high expression levels, which BnA.Hsp 70-7d of all genes had the highest transcript abundances across four tissues. Interestingly, BnC.Hsp 70-6a/6b and BnA.Hsp 70$7 a / 7 b / 7 d$ displayed high expression in leaf, suggesting that these chloroplast-localized genes may carry out related biological functions in leaf. Also, this similar higher expression pattern was also observed in different tissues. For example, $B n H s p 70-4 \mathrm{~s}$ were highly expressed specifically in leaf and flower, while BnHsp70-11s and BnHsp70-12s (except BnA.Hsp70-12e) had higher expression in stem and silique.

Furthermore, the preferential expression of $B n H s p 70$ genes and their homologs in related diploids was analyzed based on expression data between B. napus, B. rapa and B. oleracea (Fig. 5). The majority of $H s p 70$ genes in the same homologous pairs displayed distinct expression patterns. For example, BnA.Hsp70-5d was expressed at a low level among four tissues, while BrHsp 70-5a was a specific high expression in leaf. Likewise, the expression profiles of BoHsp 70-5b and BnC.Hsp 70-5c homologous pair were quite different across tissues, with a higher level in leaf and flower, respectively. Meanwhile, all 7 selective $H s p 70$ homologs (Hsp 70$5 / 9 / 10 / 13 / 15 / 16 / 17)$ were analyzed and compared. A total of $5 H s p 70$ genes identified in leaf showed the bias toward $\mathrm{C}_{\mathrm{n}}$ subgenome, whereas there were no exhibited biased expression patterns distinctly in the other three tissues. These results may help contribute to functional differentiation of $H s p 70$ gene, making the evolutionary success of polyploids and better coping with stresses in their natural environments.

\section{DISCUSSION}

The allotetraploid B. napus were generated naturally about 7500 years ago and was generally considered to have complex relationships with its diploid progenitors, $B$. rapa and B. oleracea (Chalhoub et al., 2014). In our research, all 47 BnHsp 70 genes were completely identified and analyzed based on the sequencing and assembling of Brassica genomes, while $29 \mathrm{Hsp} 70$ genes were found in B. rapa genome and 20 in B. oleracea genome (Table 1; Table S1). The polyploid 
457

458

459

460

461

462

463

464

465

466

467

468

469

470

471

472

473

474

475

476

477

478

479

480

481

482

483

484

485

486

487

488

489

490

491

492

493

494

495

496

nature of $B$. napus renders expansion of the Hsp70 gene family. Genome doubling in the form of polyploidy is followed by removal and retention of some redundant genomic material (i.e., many duplicate genes), possible variation in genomic structural characteristics and change of gene expression pattern (Adams \& Wendel, 2005). These underlying mechanisms will have played to better understand ecological success and agronomic potential of polyploid species.

\section{Genome duplications play major roles in the expansion of the $\mathrm{BnHsp70}$ gene family}

Studies have shown that members in the majority of gene family $(80 \%)$ in the model plant Arabidopsis increased during evolution, which means the gene family expansion has occurred (Lespinet et al., 2002). Gene duplication events that included whole genome duplication, chromosome fragment replication and individual gene copies, are often the crucial driving force for plant gene family expansion. In our analyses, the abundance of $H s p 70$ genes in $B$. napus may be the result of multiple gene duplication events. Previous studies revealed that the Brassica genome underwent three paleo-polyploidy events, which was the same as that of $A$. thaliana.

Furthermore, Brassica species shared an extra WGT event since isolation from Arabidopsis (Liu et al., 2014; Chalhoub et al., 2014). B. napus was formed by hybridization and polyploidization between $B$. rapa and B. oleracea which were regarded as the two ancient polyploids (Schmidt, Acarkan \& Boivin, 2001; Chalhoub et al., 2014). Compared to 18 AtHsp70 genes, B. napus genome showed significantly a higher number of $H s p 70$ genes (47 genes). Homology analysis suggested that each member of 14 AtHsp70 genes was homologous to 1-5 genes in B. napus genome (Table S1). For example, AtHsp70-12 had 5 homologs in B. napus. Correspondingly, it had 3 and 2 homologs in two diploid progenitors, B. rapa and B. oleracea, respectively.

While polyploidy is a vital mechanism of gene family expansion, tandem duplication and infrequently segmental duplication are thought to commonly evaluated mechanisms for gene family copy numbers evolution and expansion (Li et al., 2017). Therefore, it was assessed that roles of gene duplication events and Darwin's positive selection in the divergence of genes for understanding Hsp70 gene family expansion (Cannon et al., 2004). The 42 BnHsp70s were correctly mapped onto 16 chromosomes, and only one tandemly duplicated gene cluster (BnC.Hsp70-6a/6c/6d) was found (Fig. 3C). BnHsp70-6s gene clustering phenomenon was also observed in synteny analysis. A total of $46 \mathrm{BnHsp} 70$ genes were established as segmentally duplicated genes in our study, which suggested segmental duplication event may be the main mechanism in the expansion of the Hsp70 family in B. napus.

Altogether, whole genome triplication followed by main segmental duplication, played a major role in the expansion of BnHsp70 gene family (Cheng, Wu \& Wang, 2014; Chalhoub et al., 2014; Liu et al., 2014). Similar genome duplication patterns have been observed in late embryogenesis abundant ( $L E A)$ genes and Vicinal Oxygen Chelate (VOC) genes of Brassica species (Liang et al., 2016; Li et al., 2017).

\section{BnHsp70 gene loss of Large-scale mainly occurred in WGT}


497 In theory, Each $H s p 70$ gene member in Arabidopsis were expected to have three homologs in $B$. 498 rapa and $B$. oleracea after WGT event, thus leading to even more homologs in $B$. napu genome 499 (Lysak et al., 2005). However, only 47 BnHsp70 members have been identified in the present 500 study. Gene loss in large-scale had arisen on the duplicated $H s p 70$ genes after genome 501 duplication events. The synteny analysis revealed that $65.6 \%(63 / 96)$ of $H s p 70$ genes from three 502 Brassica species were located in conserved chromosomal blocks, whereas some genes were 503 deleted. Chromosomal locations also indicated that the $A_{n}\left(22\right.$ genes) and $C_{n}$ (25genes) 504 subgenomes of $B$. napus genome almost equaled that of two diploid species $B$. rapa (29 genes) 505 and B. oleracea (17 genes) (Fig. 3; Table 1; Table S1). These results demonstrated that 506 considerable loss of BnHsp70 genes mainly occurred not on recent allopolyploidization from 507 distinct diploid species, but on specific WGT which resulted in speciation and morphotype 508 diversification of Brassica plants (Town, 2006). It is worth to mention that AtHsp70-2 only had 509 one homolog (BnC.Hsp70-2) in B. napus genome, which might be due to neutral loss of 510 dispensable duplicates during the evolution process.

511 One possible explanation for gene loss could be that these genes experienced genomic 512 reshuffling during rediploidization process after WGT. Logically, extensive chromosomal 513 rearrangements after WGT mediated rediploidization and removed extra homologous 514 chromosomes during long-term natural selection (Paterson, Bowers \& Chapman, 2004; Cheng, $515 W u \&$ Wang, 2014). The gene dosage imbalance issue might also explain gene loss after WGT. 516 This hypothesis pointed out that some genes dose-changed after gene duplication had relatively 517 low retention frequencies, since they potentially altered gene product concentrations (Freeling, 518 2008). Moreover, the gene balance hypothesis provided that those genes whose products got 519 involved in the macromolecular protein complexes, signal transduction and transcription factor 520 complexes, are resistant to deletion, thus retained easily avoiding network imbalances caused by 521 loss of members (Thomas, Pedersen \& Freeling, 2006). In the long evolutionary process, this 522 hypothesis may be supported by the preferential retention of $H s p 70$ genes. Hsp 70 cytoplasm523 localized hold together to TPR protein which was the major substrate protein interacted with 524 Hsp70s, revealing Hsp70 cytoplasm-localized was probably played a key role in adaptation 525 (Usman et al., 2017). As important components of Hsp70s, the number (46) of cytoplasm526 localized protein among three Brassica species is much higher than that of localized in other 527 528

\section{Intron gain of $\mathrm{BnHsp70}$ genes and domain loss of BnHsp70 proteins}

530 Compared to non-orthologous gene sequences, orthologous genes tend to have more conserved 531 intron positions (Henricson, Forslund \& Sonnhammer, 2010). In this study, 10 out of 25 532 orthologs in $B$. napus that have a conserved intron number and intron phase corresponding to 533 ancestral genes in B. rapa and B. oleracea (Figs. 2A and 2B). However, 7 BnHsp 70 genes 534 corresponding to their progenitor genes were found to have gained introns in the coding 535 sequence, and no introns have been lost in all orthologs. This observation is suggestive of intron 536 gain events in $H s p 70$ genes during hybridization and polyploidization. Also, the rate of gain/loss 
537 in intron is higher than that of exons in view of the lower selection pressure in intron sequences 538 (Lin et al., 2006). Generally, variation of the number and placement of intron is a common 539 process that has occurred during evolution (Roy \& Gilbert, 2005; Jeffares, Mourier \& Penny, 540 2006; Rogozin et al., 2012). Furthermore, the factors that determine the evolutionary fate of 541 intron count on the intron itself, the gene in which it exists and the host organism (Jeffares,

542 Mourier \& Penny, 2006). We suggest that intron additions of orthologs in BnHsp70 family are a 543 mechanism of allopolyploid adaptation, which is beneficial to conquer genomic shock generated 544 from hybridization event that two differentiated diploid genomes reunited in a common nucleus 545 of B. napus genome. Introns are essential functional components of eukaryotic genomes.

546 Interestingly, a higher number of introns in rice can lead to a higher expression levels by

547

548

549

550

551

552

553

554

555

556

557

558

559

560

561

562

563

564

565

566

567

568

569

570

571

572

573

574

575

576 providing post-transcriptional stability for mRNA (Deshmukh, Sonah \& Singh 2016). Thus, intron gains in $7 \mathrm{BnHsp} 70$ genes may increase the diversity of gene function to varying extents, which may have contributed to being given higher phenotypic plasticity of $B$. napus than two progenitor species. Meanwhile, it was obviously observed that the intron length of BnA.Hsp 70$4 c$ was truncated compared with orthologous gene $B r H s p 70-4 b$ (Fig. 2B), which may influence their mode of expression (Chorev \& Carmel, 2012). There are evidence that variation in the intron length appears to affect the frequency and type of alternative splicing, and longer introns are more likely to undergo alternative splicing and no splicing (Fox-Walsh et al., 2005; Kim, Magen \& Ast, 2007). We think that changes in intron length may help to optimize $H s p 70$ gene structure and function and facilitate the evolution of species after polyploidization. In summary, intron dynamics in $H s p 70$ gene family reveal common or differing trends in B. napus genome evolution following polyploidy.

Previous research demonstrated that more than one-third of all domains have a marked tendency to increase/decrease in size in protein evolution statistically (Wolf et al., 2007). Our orthologs analyses clearly showed 17 out of 25 orthologous BnHsp70 proteins had similar motif composition, indicating conservation of domain in BnHsp70s was highly consistent with that in two diploid species and also emphasizing their close evolution relationship in three Brassica species. BnC.Hsp70-5c and BnA.Hsp70-5d had both lost motif 6 compared with their orthologs BoHsp70-5b and BrHsp70-5a, while BnA.Hsp70-13a had lost motif 5 compared with BrHsp7013. Consequently, three BnHsp70 proteins lost their conserved NBD domain of fragment due to typical signature sequences included by motif 6 and motif 5 . Except for the effects of erroneous annotations, we can consider domain loss of fragment represents protein evolution of BnHsp70 family in the long-term polyploidy adaptation.

\section{Subgenome bias of $\mathrm{Hsp} 70$ genes in $\mathrm{B}$. napus and expression of $\mathrm{BnHsp70}$} members under diverse stress

After breaking down the hybridization barrier and undergoing genomic shock, the B. napus genome has become a stable genome which may allow considerable subgenome interaction (McClintock, 1984). As one of the widespread consequences of subgenome interaction, gene conversion between two subgenomes routinely refers to transfer genetic information between

Peer) reviewing PDF | (2019:03:35674:3:0:NEW 13 Jul 2019) 
577 genes by a unidirectional approach (Samans, Chalhoub \& Snowdon, 2017). Using the gene 578 conversion dataset previously published, homologous gene conversion arose in BnC.Hsp70-6a $579\left(\mathrm{C}_{\mathrm{n}} 01\right)$ and BnA.Hsp70-7a $\left(\mathrm{A}_{\mathrm{n}} 01\right)$, and this result took place with the $\mathrm{A}_{\mathrm{n}}$ subgenome as a donor 580 (Chalhoub et al., 2014), which were also proved by genomic distribution and synteny analysis of 581 BnHsp70 gene clustering. As a outcome of allopolyploidization, similar conversion tendency at 582 the whole-genome level were described previously in B. napus that the significant directional 583 bias from subgenome $A_{n}$ to $C_{n}$ was nearly 1.3 times than the other direction and the highest 584 rearrangement frequency was also found in the homologous chromosome pair $A_{n} 01-C_{n} 01$ 585 (Chalhoub et al., 2014). In allopolyploid cotton (Gossypium hirsutum L.), similar homologous

586

587

588

589

590

591

592

593

594

595

596

597

598

599

600

601

602

603

604

605

606

607

608

609

610

611

612

613

614

615

616 gene conversion events occurred biasedly from the A subgenome to D subgenome of agronomically inferior (Paterson et al., 2012). In addition, subgenome bias was also detected for gene expression. There were a total of 5 Hsp 70 genes (Hsp70-5/9/10/13/17) showed the bias toward $\mathrm{C}_{\mathrm{n}}$ subgenome when the silique transcripts were analyzed by RNA-seq in our study, whereas no significant expression bias was observed in the other three tissues. This revealed a gene expression bias related to tissue-by-subgenome interactions. Allohexaploid wheat arose as hybridization and polyploidization between Triticum turgidum (AABB) and Aegilops tauschii (DD), but the previous research showed AB- and D-subgenome were globally dominant to genes participating in the development and involving in adaptation, respectively ( Li et al., 2014). Here, gene conversion event and biased gene expression were observed in the $H s p 70$ gene family of $B$. napus genome, demonstrating that subgenome bias might be prevalent influence between fused genomes by hybridization in polyploid species. This genetic bias may be contributed to polyploids survival and success, or even drive genetic diversification in polyploid species (Otto, 2007; Samans, Chalhoub \& Snowdon, 2017). As for the cause of subgenome bias or dominance, more detailed studies are expected to confirm them.

In plants, $H s p 70$ genes strongly associated with various stress resistance, also play key roles in the allopolyploid B. napus. In B.napus (cv. Zhongshuang 9), the expression profile of 20-daysold siliques underlying heat response showed that there were many considerable numbers of heat-responsive genes are up-regulation or induced to expression as the heat treatment results $(Y u$ et al., 2014). In particular, 18 of all 32 up-regulated BnHsp70 genes exhibited over 10-fold increased expression, implying up-regulation or activation of $\mathrm{BnHsp} 70$ genes in siliques may be important responses for the acquisition of thermotolerance during reproductive stages. In a relatively drought tolerant $B$. napus (cv. Q2), 6018 and 5377 differentially expressed genes (DEGs) were detected in root and leaf in response to drought stress, and all detected 12 Hsp 70 genes were up-regulated expression (Liu et al., 2015). Based on previous published data (Liu et $a l ., 2015)$, combined with the potentially reliable homologous pairs shown in Figure 2, gene expression of $H s p 70$ gene family in $B$. napus under drought stress was analyzed. By comparison, we found that BnA.Hsp70-4c and BnA.Hsp70-10a exhibited up-regulated patterns in root, whereas BnA.Hsp70-5d and BnA.Hsp70-8a showed up-regulation in leaf. In summary, Hsp70s in allopolyploid $B$. napus are believed to be involved in the diverse stress process and provide valuable information for the further development of the adversity-resistance breeding in rapeseed.

Peer) reviewing PDF | (2019:03:35674:3:0:NEW 13 Jul 2019) 


\section{CONCLUSIONS}

619 This study primarily discussed identification, phylogenetic classification, molecular evolution 620 and gene expression analyses of the $H s p 70$ gene family in B. napus and diploid B. rapa and B. 621 oleracea. All of the 47 BnHsp 70, 29 BrHsp70 and 20 BoHsp70 genes were identified based on

622 the published genome sequencing results. The Hsp70 family could be classified into six

623 subfamilies in the phylogenetic tree. By the comparison of 25 Hsp 70 gene orthologs in B. napus

624 with diploid progenitors, most exon-intron distribution and conserved motifs were conserved

625 among the same subfamilies. With large-scale gene loss during evolution, WGT and segmental

626 duplication events contributed the most to expansion of $H s p 70$ genes in Brassica. Expression

627 analysis of $H s p 70$ genes indicated their tissue-specific expression profiles and $\mathrm{C}_{\mathrm{n}}$ subgenome

628 biased expression. This work facilitates future functional and evolutionary analysis of the Hsp70

629 family in many polyploid species.

630

\section{REFERENCES}

632

633

634

635

636

637

638

639

640

641

642

643

644

645

646

647

648

649

650

651

652

653

654

655

656

657

658

659

660

Adams KL, Wendel JF. 2005. Polyploidy and genome evolution in plants. Current Opinion in Plant Biology 8(2):135-141 DOI 10.1016/j.pbi.2005.01.001.

Ali MK, Azhar A, Salam EU, Galani S. 2017. Differential expression of molecular chaperon (Hsp70) and antioxidant enzymes: inducing thermotolerance in rice(Oryza Sativa L.). Pakistan Journal of Botany 49:229-238.

Bailey TL, Boden M, Buske FA, Frith M, Grant CE, Clementi L, Ren J, Li WW, Noble WS. 2009. MEME SUITE: tools for motif discovery and searching. Nucleic Acids Research 37(Web Server issue):W202-208 DOI 10.1093/nar/gkp335.

Beck EH, Fettig S, Knake C, Hartig K, Bhattarai T. 2007. Specific and unspecific responses of plants to cold and drought stress. Journal of Biosciences 32(3):501-510.

Bird KA, VanBuren R, Puzey JR, Edger PP. 2018. The causes and consequences of subgenome dominance in hybrids and recent polyploids. New Phytologist 220(1):87-93 DOI 10.1111/nph.15256.

Boettcher U, Rampin E, Hartmann K, Zanetti F, Flenet F, Morison M, Kage H. 2016. A phenological model of winter oilseed rape according to the BBCH scale. Crop \& Pasture Science 67(3-4):345-358 DOI 10.1071/cp15321.

Cannon SB, Mitra A, Baumgarten A, Young ND, May G. 2004. The roles of segmental and tandem gene duplication in the evolution of large gene families in Arabidopsis thaliana. BMC Plant Biology 4:10 DOI 10.1186/1471-2229-4-10.

Chalhoub B, Denoeud F, Liu S, Parkin IAP, Tang H, Wang X, Chiquet J, Belcram H, Tong C, Samans B. 2014. Early allopolyploid evolution in the post-Neolithic Brassica napus oilseed genome. Science 345(6199):950-953.

Cheng F, Liu S, Wu J, Fang L, Sun S, Liu B, Li P, Hua W, Wang X. 2011. BRAD, the genetics and genomics database for Brassica plants. BMC Plant Biology 11:136 DOI 10.1186/1471-2229-11-136.

Cheng F, Wu J, Fang L, Wang X. 2012. Syntenic gene analysis between Brassica rapa and other Brassicaceae species. Frontiers in Plant Science 3 DOI 10.3389/fpls.2012.00198.

Cheng F, Wu J, Wang X. 2014. Genome triplication drove the diversification of Brassica plants. Horticulture Research 1 DOI 10.1038/hortres.2014.24. 
661

662

663

664

665

666

667

668

669

670

671

672

673

674

675

676

677

678

679

680

681

682

683

684

685

686

687

688

689

690

691

692

693

694

695

696

697

698

699

700

701

702

703

704

Chorev M, Carmel L. 2012. The function of introns. Frontiers in genetics 3:55 DOI 10.3389/fgene.2012.00055.

Deng W, Wang Y, Liu Z, Cheng H, Xue Y. 2014. HemI: A Toolkit for Illustrating Heatmaps. PloS One 9(11) DOI 10.1371/journal.pone.0111988.

Deshmukh RK, Sonah H, Singh NK. 2016. Intron gain, a dominant evolutionary process supporting high levels of gene expression in rice. Journal of Plant Biochemistry and Biotechnology 25(2):142-146 DOI 10.1007/s13562-015-0319-5.

Eddy SR. 2009. A new generation of homology search tools based on probabilistic inference. Genome informatics International Conference on Genome Informatics 23(1):205-211.

Feder ME, Hofmann GE. 1999. Heat-shock proteins, molecular chaperones, and the stress response: Evolutionary and ecological physiology. Annual Review of Physiology 61:243-282 DOI 10.1146/annurev.physiol.61.1.243.

Finn RD, Coggill P, Eberhardt RY, Eddy SR. 2016. The Pfam protein familiedatabase: towards a more sustainable future. Nucleic Acids Research 44(D1):D279-285 DOI 10.1093/nar/gkv1344.

Fox-Walsh KL, Dou YM, Lam BJ, Hung SP, Baldi PF, Hertel KJ. 2005. The architecture of pre-mRNAs affects mechanisms of splice-site pairing. Proceedings of the National Academy of Sciences of the United States of America 102(45):16176-16181 DOI 10.1073/pnas.050849102.

Freeling M. 2008. The evolutionary position of subfunctionalization, downgraded. Genome Dynamics 4:25-40 DOI 10.1159/000126004.

Guo M, Liu JH, Ma X, Zhai YF, Gong ZH, Lu MH. 2016. Genome-wide analysis of the Hsp70 family genes in pepper (Capsicum annuum L.) and functional identification of CaHsp70-2 involvement in heat stress. Plant Science 252:246-256 DOI 10.1016/j.plantsci.2016.07.001.

Habekotte B. 1997. A model of the phenological development of winter oilseed rape (Brassica napus L.). Field Crops Research 54(2-3):127-136 DOI 10.1016/s0378-4290(97)00043-9.

Henricson A, Forslund K, Sonnhammer ELL. 2010. Orthology confers intron position conservation. BMC Genomics 11 DOI 10.1186/1471-2164-11-412.

Horton P, Park KJ, Obayashi T, Fujita N, Harada H, Adams-Collier CJ, Nakai K. 2007. WoLF PSORT: protein localization predictor. Nucleic Acids Research 35(Web Server issue):W585-587 DOI 10.1093/nar/gkm259.

Hu B, Jin J, Guo AY, Zhang H, Luo J, Gao G. 2015. GSDS 2.0: an upgraded gene feature visualization server. Bioinformatics 31(8):1296-1297 DOI 10.1093/bioinformatics/btu817.

Jeffares DC, Mourier T, Penny D. 2006. The biology of intron gain and loss. Trends in Genetics 22(1):16-22 DOI 10.1016/j.tig.2005.10.006.

Jungkunz I, Link K, Vogel F, Voll LM, Sonnewald S, Sonnewald U. 2011. AtHsp70-15deficient Arabidopsis plants are characterized by reduced growth, a constitutive cytosolic protein response and enhanced resistance to TuMV. Plant Journal 66(6):983-995.

Katoh K, Rozewicki J, Yamada KD. 2017. MAFFT online service: multiple sequence alignment, interactive sequence choice and visualization. Briefings in Bioinformatics DOI 10.1093/bib/bbx108.

Kim E, Magen A, Ast G. 2007. Different levels of alternative splicing among eukaryotes. Nucleic Acids Research 35(1):125-131 DOI 10.1093/nar/gk1924.

Peer] reviewing PDF | (2019:03:35674:3:0:NEW 13 Jul 2019) 
705

706

707

708

709

710

711

712

713

714

715

716

717

718

719

720

721

722

723

724

725

726

727

728

729

730

731

732

733

734

735

736

737

738

739

740

741

742

743

744

745

746

747

748

749

Krzywinski M, Schein J, Birol I, Connors J, Gascoyne R, Horsman D, Jones SJ, Marra MA. 2009. Circos: an information aesthetic for comparative genomics. Genome Research 19(9): 1639-1645 DOI 10.1101/gr.092759.109.

Kumar S, Stecher G, Tamura K. 2016. MEGA7: Molecular evolutionary genetics analysis version 7.0 for bigger datasets. Molecular Biology and Evolution 33(7):1870-1874 DOI $10.1093 / \mathrm{molbev} / \mathrm{msw} 054$.

Lamesch P, Berardini TZ, Li D, Swarbreck D, Wilks C, Sasidharan R, Muller R, Dreher K, Alexander DL, Garcia-Hernandez M, Karthikeyan AS, Lee CH, Nelson WD, Ploetz L, Singh S, Wensel A, Huala E. 2012. The Arabidopsis Information Resource (TAIR): improved gene annotation and new tools. Nucleic Acids Research 40(Database issue):D12021210 DOI 10.1093/nar/gkr1090.

Leng L, Liang Q, Jiang J, Zhang C, Hao Y, Wang X, Su W. 2017. A subclass of HSP70s regulate development and abiotic stress responses in Arabidopsis thaliana. Journal of Plant Research 130(2):349-363 DOI 10.1007/s10265-016-0900-6.

Lescot M, Dehais P, Thijs G, Marchal K, Moreau Y, Van de Peer Y, Rouze P, Rombauts S. 2002. PlantCARE, a database of plant cis-acting regulatory elements and a portal to tools for in silico analysis of promoter sequences. Nucleic Acids Research 30(1):325-327.

Lespinet O, Wolf YI, Koonin EV, Aravind L. 2002. The role of lineage-specific gene family expansion in the evolution of eukaryotes. Genome Research 12(7):1048-1059 DOI 10.1101/gr.174302.

Letunic I, Bork P. 2016. Interactive tree of life (iTOL) v3: an online tool for the display and annotation of phylogenetic and other trees. Nucleic Acids Research 44(W1):W242-245 DOI 10.1093/nar/gkw290.

Letunic I, Copley RR, Schmidt S, Ciccarelli FD, Doerks T, Schultz J, Ponting CP, Bork P. 2004. SMART 4.0: towards genomic data integration. Nucleic Acids Research 32(Database issue):D142-144 DOI 10.1093/nar/gkh088.

Li AL, Liu DC, Wu J, Zhao XB, Hao M, Geng SF, Yan J, Jiang XX, Zhang LQ, Wu JY, Yin LJ, Zhang RZ, Wu L, Zheng YL, Mao L. 2014. mRNA and small RNA transcriptomes reveal insights into dynamic homoeolog regulation of allopolyploid heterosis in nascent hexaploid wheat. Plant Cell 26(5):1878-1900 DOI 10.1105/tpc.114.124388.

Li B, Dewey CN. 2011. RSEM: accurate transcript quantification from RNA-Seq data with or without a reference genome. BMC Bioinformatics 12 DOI 10.1186/1471-2105-12-323.

Li M, Wang R, Liu Z, Wu X, Wang J. 2019. Genome-wide identification and analysis of the WUSCHEL-related homeobox (WOX) gene family in allotetraploid Brassica napus reveals changes in WOX genes during polyploidization. BMC Genomics 20 DOI 10.1186/s12864-0195684-3.

Liang Y, Wan N, Cheng Z, Mo Y, Liu B, Liu H, Raboanatahiry N, Yin Y, Li M. 2017. Whole-genome identification and expression pattern of the vicinal oxygen chelate family in rapeseed (Brassica napus L.). Frontiers in Plant Science 8 DOI 10.3389/fpls.2017.00745.

Liang Y, Xiong ZY, Zheng JX, Xu DY, Zhu ZY, Xiang J, Gan JP, Raboanatahiry N, Yin YT, Li MT. 2016. Genome-wide identification, structural analysis and new insights into late embryogenesis abundant ( $L E A)$ gene family formation pattern in Brassica napus. Scientific Reports 6 DOI 10.1038/srep24265.

Librado P, Rozas J. 2009. DnaSP v5: a software for comprehensive analysis of DNA polymorphism data. Bioinformatics 25(11): 1451-1452 DOI 10.1093/bioinformatics/btp187.

PeerJ reviewing PDF | (2019:03:35674:3:0:NEW 13 Jul 2019) 
750

751

752

753

754

755

756

757

758

759

760

761

762

763

764

765

766

767

768

769

770

771

772

773

774

775

776

777

778

779

780

781

782

783

784

785

786

787

788

789

790

791

792

793

794

795

Lin BL, Wang JS, Liu HC, Chen RW, Meyer Y, Barakat A, Delseny M. 2001. Genomic analysis of the Hsp70 superfamily in Arabidopsis thaliana. Cell Stress \& Chaperones 6(3):201-208.

Lindquist S. 1986. The heat-shock response. Annual Review of Biochemistry 55:1151-1191 DOI 10.1146/annurev.bi.55.070186.005443.

Lin HN, Zhu W, Silva JC, Gu X, Buell CR. 2006. Intron gain and loss in segmentally duplicated genes in rice. Genome Biology 7(5) DOI 10.1186/gb-2006-7-5-r41.

Liu C, Zhang X, Zhang K, An H, Hu K, Wen J, Shen J, Ma C, Yi B, Tu J, Fu T. 2015. Comparative analysis of the Brassica napus root and leaf transcript profiling in response to drought stress. International Journal of Molecular Sciences 16(8):18752-18777 DOI 10.3390/ijms160818752.

Liu Q, Hendrickson WA. 2007. Insights into Hsp70 chaperone activity from a crystal structure of the yeast Hsp110 Sse1. Cell 131(1):106-120 DOI 10.1016/j.cell.2007.08.039.

Liu S, Liu Y, Yang X, Tong C, Edwards D, Parkin IAP, Zhao M, Ma J, Yu J, Huang S, Wang X, Wang J, Lu K, Fang Z, Bancroft I, Yang T-J, Hu Q, Wang X, Yue Z, Li H, Yang L, Wu J, Zhou Q, Wang W, King GJ, Pires JC, Lu C, Wu Z, Sampath P, Wang Z, Guo H, Pan S, Yang L, Min J, Zhang D, Jin D, Li W, Belcram H, Tu J, Guan M, Qi C, Du D, Li J, Jiang L, Batley J, Sharpe AG, Park B-S, Ruperao P, Cheng F, Waminal NE, Huang Y, Dong C, Wang L, Li J, Hu Z, Zhuang M, Huang Y, Huang J, Shi J, Mei D, Liu J, Lee T-H, Wang J, Jin H, Li Z, Li X, Zhang J, Xiao L, Zhou Y, Liu Z, Liu X, Qin R, Tang X, Liu W, Wang Y, Zhang Y, Lee J, Kim HH, Denoeud F, Xu X, Liang X, Hua W, Wang X, Wang J, Chalhoub B, Paterson AH. 2014. The Brassica oleracea genome reveals the asymmetrical evolution of polyploid genomes. Nature Communications $\mathbf{5}$ DOI 10.1038/ncomms4930.

Lysak MA, Koch MA, Pecinka A, Schubert I. 2005. Chromosome triplication found across the tribe Brassiceae. Genome Research 15(4):516-525 DOI 10.1101/gr.3531105.

Marchler-Bauer A, Derbyshire MK, Gonzales NR, Lu S, Chitsaz F, Geer LY, Geer RC, He J, Gwadz M, Hurwitz DI, Lanczycki CJ, Lu F, Marchler GH, Song JS, Thanki N, Wang Z, Yamashita RA, Zhang D, Zheng C, Bryant SH. 2015. CDD: NCBI's conserved domain database. Nucleic Acids Research 43(Database issue):D222-226 DOI 10.1093/nar/gku1221.

Masterson J. 1994. Stomatal size in fossil plants-evidence for polyploidy in majority of angiosperms. Science 264(5157):421-424 DOI 10.1126/science.264.5157.421.

Mayer MP, Bukau B. 2005. Hsp70 chaperones: cellular functions and molecular mechanism. Cellular and Molecular Life Sciences 62(6):670-684 DOI 10.1007/s00018-004-4464-6.

McClintock B. 1984. The significance of responses of the genome to challenge. Science 226(4676): 792-801 DOI 10.1126/science. 15739260.

Mitchell A, Chang HY, Daugherty L, Fraser M, Hunter S, Lopez R, McAnulla C, McMenamin C, Nuka G, Pesseat S, Sangrador-Vegas A, Scheremetjew M, Rato C, Yong SY, Bateman A, Punta M, Attwood TK, Sigrist CJ, Redaschi N, Rivoire C, Xenarios I, Kahn D, Guyot D, Bork P, Letunic I. 2015. The InterPro protein families database: the classification resource after 15 years. Nucleic Acids Research 43(Database issue):D213-221 DOI 10.1093/nar/gku1243.

Otto SP. 2007. The evolutionary consequences of polyploidy. Cell 131(3):452-462 DOI 10.1016/j.cell.2007.10.022.

Paterson AH, Bowers JE, Chapman BA. 2004. Ancient polyploidization predating divergence of the cereals, and its consequences for comparative genomics. Proceedings of the National 
796

797

798

799

800

801

802

803

804

805

806

807

808

809

810

811

812

813

814

815

816

817

818

819

820

821

822

823

824

825

826

827

828

829

830

831

832

833

834

835

836

837

838

839

840

841

Academy of Sciences of the United States of America 101(26):9903-9908 DOI 10.1073/pnas.0307901101.

Paterson AH, Wendel JF, Gundlach H, Guo H, Jenkins J, Jin D, Llewellyn D, Showmaker KC, Shu S, Udall J, Yoo M-j, Byers R, Chen W, Doron-Faigenboim A, Duke MV, Gong L, Grimwood J, Grover C, Grupp K, Hu G, Lee T-h, Li J, Lin L, Liu T, Marler BS, Page JT, Roberts AW, Romanel E, Sanders WS, Szadkowski E, Tan X, Tang H, Xu C, Wang J, Wang Z, Zhang D, Zhang L, Ashrafi H, Bedon F, Bowers JE, Brubaker CL, Chee PW, Das S, Gingle AR, Haigler CH, Harker D, Hoffmann LV, Hovav R, Jones DC, Lemke C, Mansoor S, Rahman MU, Rainville LN, Rambani A, Reddy UK, Rong J-k, Saranga Y, Scheffler BE, Scheffler JA, Stelly DM, Triplett BA, Van Deynze A, Vaslin MFS, Waghmare VN, Walford SA, Wright RJ, Zaki EA, Zhang T, Dennis ES, Mayer KFX, Peterson DG, Rokhsar DS, Wang X, Schmutz J. 2012. Repeated polyploidization of Gossypium genomes and the evolution of spinnable cotton fibres. Nature 492(7429):423-+ DOI 10.1038/nature11798.

Rogozin IB, Carmel L, Csuros M, Koonin EV. 2012. Origin and evolution of spliceosomal introns. Biology Direct 7 DOI 10.1186/1745-6150-7-11.

Roy SW, Gilbert W. 2005. Rates of intron loss and gain: Implications for early eukaryotic evolution. Proceedings of the National Academy of Sciences of the United States of America 102(16):5773-5778 DOI 10.1073/pnas.0500383102.

Samans B, Chalhoub B, Snowdon RJ. 2017. Surviving a genome collision: genomic signatures of allopolyploidization in the recent crop species Brassica napus. Plant Genome 10(3) DOI 10.3835/plantgenome2017.02.0013.

Sarkar NK, Kundnani P, Grover A. 2013. Functional analysis of $H s p 70$ superfamily proteins of rice (Oryza sativa). Cell Stress \& Chaperones 18(4):427-437 DOI 10.1007/s12192-0120395-6.

Schmidt R, Acarkan A, Boivin K. 2001. Comparative structural genomics in the Brassicaceae family. Plant Physiology and Biochemistry 39(3-4):253-262 DOI 10.1016/s09819428(01)01239-6.

Su P-H, Li H-m. 2008. Arabidopsis stromal 70-kD heat shock proteins are essential for plant development and important for thermotolerance of germinating seeds. Plant Physiology 146(3):1231-1241 DOI 10.1104/pp.107.114496.

Sung DY, Vierling E, Guy CL. 2001. Comprehensive expression profile analysis of the Arabidopsis hsp70 gene family. Plant Physiology 126(2):789-800 DOI 10.1104/pp.126.2.789.

Thomas BC, Pedersen B, Freeling M. 2006. Following tetraploidy in an Arabidopsis ancestor, genes were removed preferentially from one homeolog leaving clusters enriched in dosesensitive genes. Genome Research 16(7):934-946 DOI 10.1101/gr.4708406.

Town CD, Cheung F, Maiti R, Crabtree J, Haas BJ, Wortman JR, Hine EE, Althoff R, Arbogast TS, Tallon LJ, Vigouroux M, Trick M, Bancroft I. 2006. Comparative genomics of Brassica oleracea and Arabidopsis thaliana reveal gene loss, fragmentation, and dispersal after polyploidy. Plant Cell 18(6):1348-1359 DOI 10.1105/tpc.106.041665.

Usman MG, Rafii MY, Martini MY, Yusuff OA, Ismail MR, Miah G. 2017. Molecular analysis of Hsp70 mechanisms in plants and their function in response to stress. Biotechnology and Genetic Engineering Reviews 33(1):26-39.

Wang R, Li M, Wu X, Wang J. 2019. The gene structure and expression level changes of the GH3 gene family in Brassica napus relative to its diploid ancestors. Genes 10(1) DOI 10.3390/genes 10010058 .

Peer) reviewing PDF | (2019:03:35674:3:0:NEW 13 Jul 2019) 
842 Wang W, Vinocur B, Shoseyov O, Altman A. 2004. Role of plant heat-shock proteins and 843 molecular chaperones in the abiotic stress response. Trends in Plant Science 9(5):244-252 844 DOI 10.1016/j.tplants.2004.03.006.

845 Waterhouse AM, Procter JB, Martin DM, Clamp M, Barton GJ. 2009. Jalview Version 2--a

846 multiple sequence alignment editor and analysis workbench. Bioinformatics 25(9):1189-1191

847 DOI 10.1093/bioinformatics/btp033.

848 Wilkins MR, Gasteiger E, Bairoch A, Sanchez JC, Williams KL, Appel RD, Hochstrasser

849 DF. 1999. Protein identification and analysis tools in the ExPASy server. Methods in

$850 \quad$ Molecular Biology 112:531-552.

851 Wolf Y, Madej T, Babenko V, Shoemaker B, Panchenko AR. 2007. Long-term trends in

852

853

854

855

856

857

858

859

860

861

862

863

864

865

866 evolution of indels in protein sequences. BMC Evolutionary Biology 7 DOI 10.1186/14712148-7-19.

Yang Z, Gu S, Wang X, Li W, Tang Z, Xu C. 2008. Molecular evolution of the $C P P$-like gene family in plants: insights from comparative genomics of Arabidopsis and rice. Journal of Molecular Evolution 67(3):266-277 DOI 10.1007/s00239-008-9143-z.

Yu E, Fan C, Yang Q, Li X, Wan B, Dong Y, Wang X, Zhou Y. 2014. Identification of heat responsive genes in Brassica napus siliques at the seed-filling stage through transcriptional profiling. PloS One 9(7) DOI 10.1371/journal.pone.0101914.

Zhang L, Zhao HK, Dong QL, Zhang YY, Wang YM, Li HY, Xing GJ, Li QY, Dong YS. 2015. Genome-wide analysis and expression profiling under heat and drought treatments of HSP70 gene family in soybean (Glycine max L.). Frontiers in Plant Science 6:773 DOI 10.3389/fpls.2015.00773.

Zhou T, Wang Y, Chen JQ, Araki H, Jing Z, Jiang K, Shen J, Tian D. 2004. Genome-wide identification of $N B S$ genes in japonica rice reveals significant expansion of divergent non-

867

868 TIR NBS-LRR genes. Molecular Genetics and Genomics 271(4):402-415 DOI 10.1007/s00438-004-0990-z.

869

870

Zhu X, Zhao X, Burkholder WF, Gragerov A, Ogata CM, Gottesman ME, Hendrickson WA. 1996. Structural analysis of substrate binding by the molecular chaperone DnaK. Science 272(5268):1606-1614. 


\section{Figure 1}

Figure 1 Phylogenetic analysis of the B. napus (cv. Darmor-bzh), B. rapa (cv. Chiifu-401-42), $B$. oleracea (var. capitata line 02-12) and $A$. thaliana Hsp70 proteins.

The full-length amino acid sequences of the Hsp70 proteins were aligned using MUSCLE program in MEGA 7.0. The unrooted tree was generated by the neighbor-joining (NJ) method with 1000 bootstrap replicates. All Hsp70 proteins were divided to A-F subfamilies, which were distinguished by different colors. Bootstrap values which were above $50 \%$ are indicated at the base of each subfamily. 


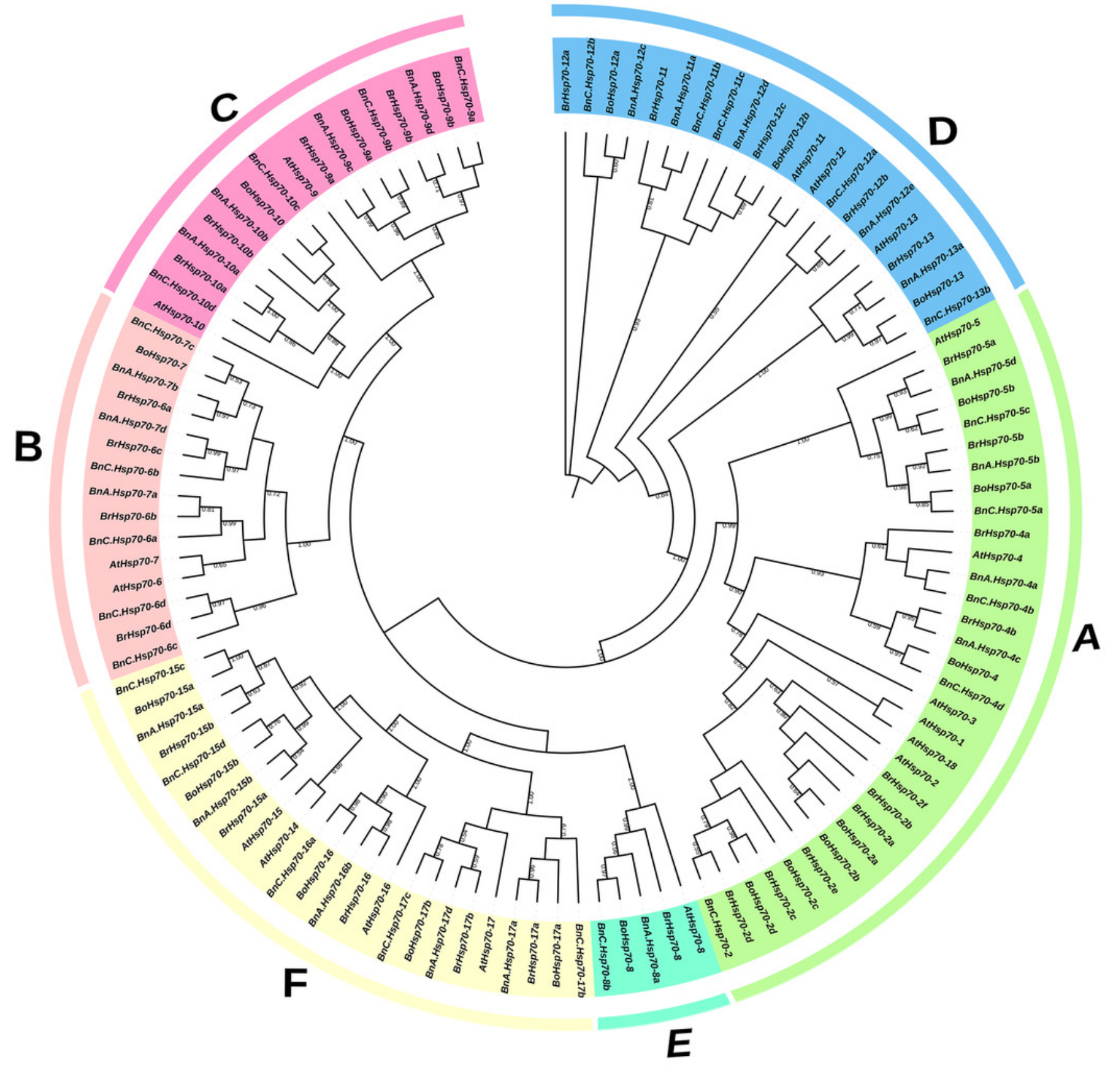




\section{Figure 2}

Characterizations of the identified Hsp70s in B. napus, B. rapa and B. oleracea.

The characterizations include intron/exon structure and conserved protein motif location. All Hsp70s were arranged based on similarity of amino acid sequences on each subfamily. (A) The characterizations of the Hsp70s in the subfamily A. (B) The characterizations of the Hsp70s in the subfamily B. (C) The characterizations of the Hsp70s in the subfamily C. (D) The characterizations of the Hsp70s in the subfamily D. (E) The characterizations of the Hsp70s in the subfamily E. (F) The characterizations of the Hsp70s in the subfamily F. The 25 reliable orthologous pairs between $B$. napus and two progenitors were highlighted by red branch. Blue boxes indicate exons and black lines represent introns. The gene length was estimated by horizontal axis of the bottom in the gene structure analysis (GSDS: http://gsds.cbi.pku.edu.cn/). Twenty motifs were identified through MEME analysis (http://meme-suite.org/). 

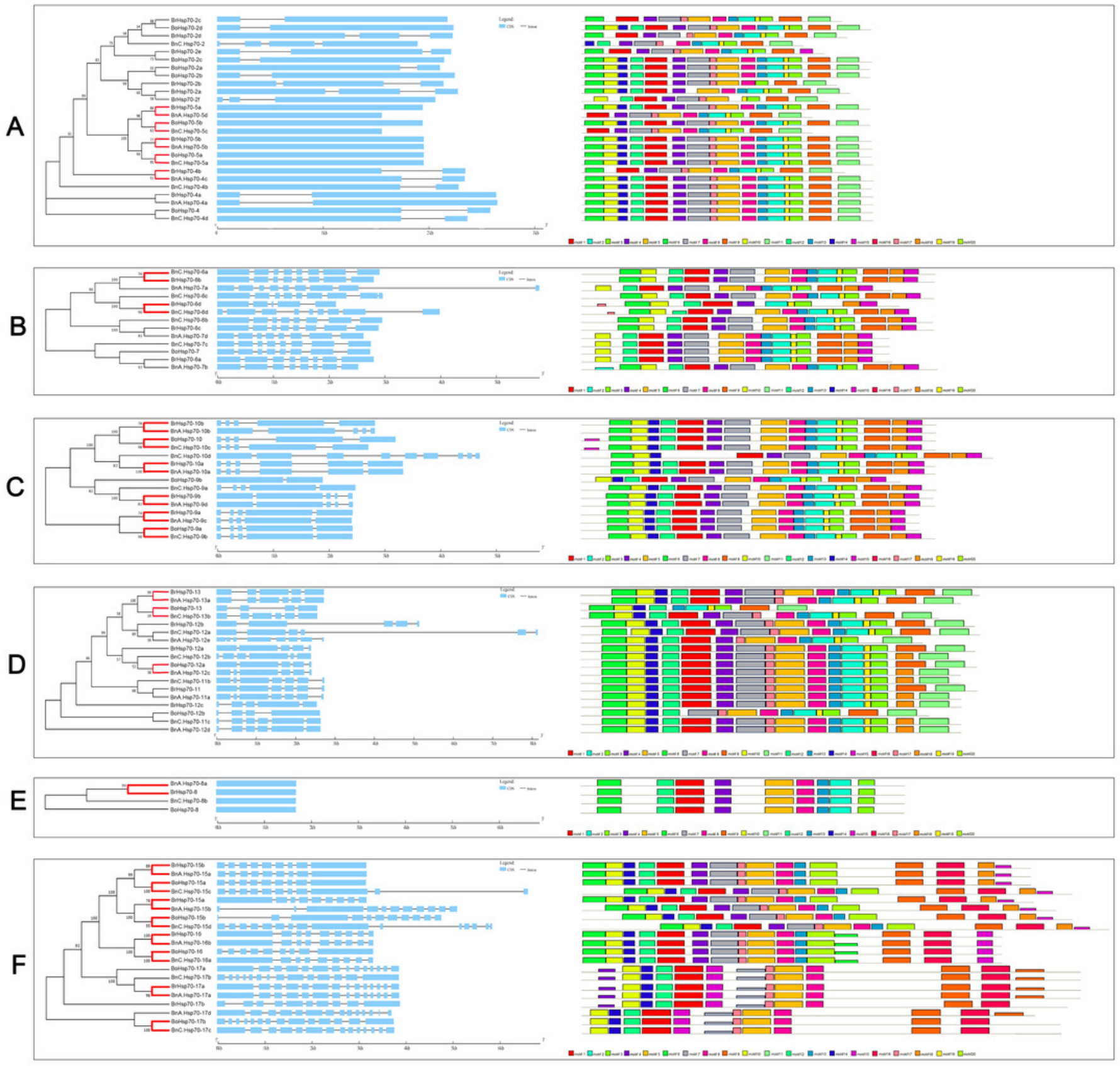


\section{Figure 3}

Distribution of $H s p 70$ gene family members on $B$. napus, $B$. rapa and $B$. oleracea chromosomes.

Distribution of $H s p 70$ gene family members on $B$. rapa (A), B. oleracea (B) and B. napus (C) chromosomes. Some genes were not shown because these genes located on unmapped chromosomes. The chromosome name was indicated at the top of each bar. Tandem arrays of Hsp70 genes were displayed within the blue frame. The scale of all chromosomes was in millions of base $(\mathrm{Mb})$. 

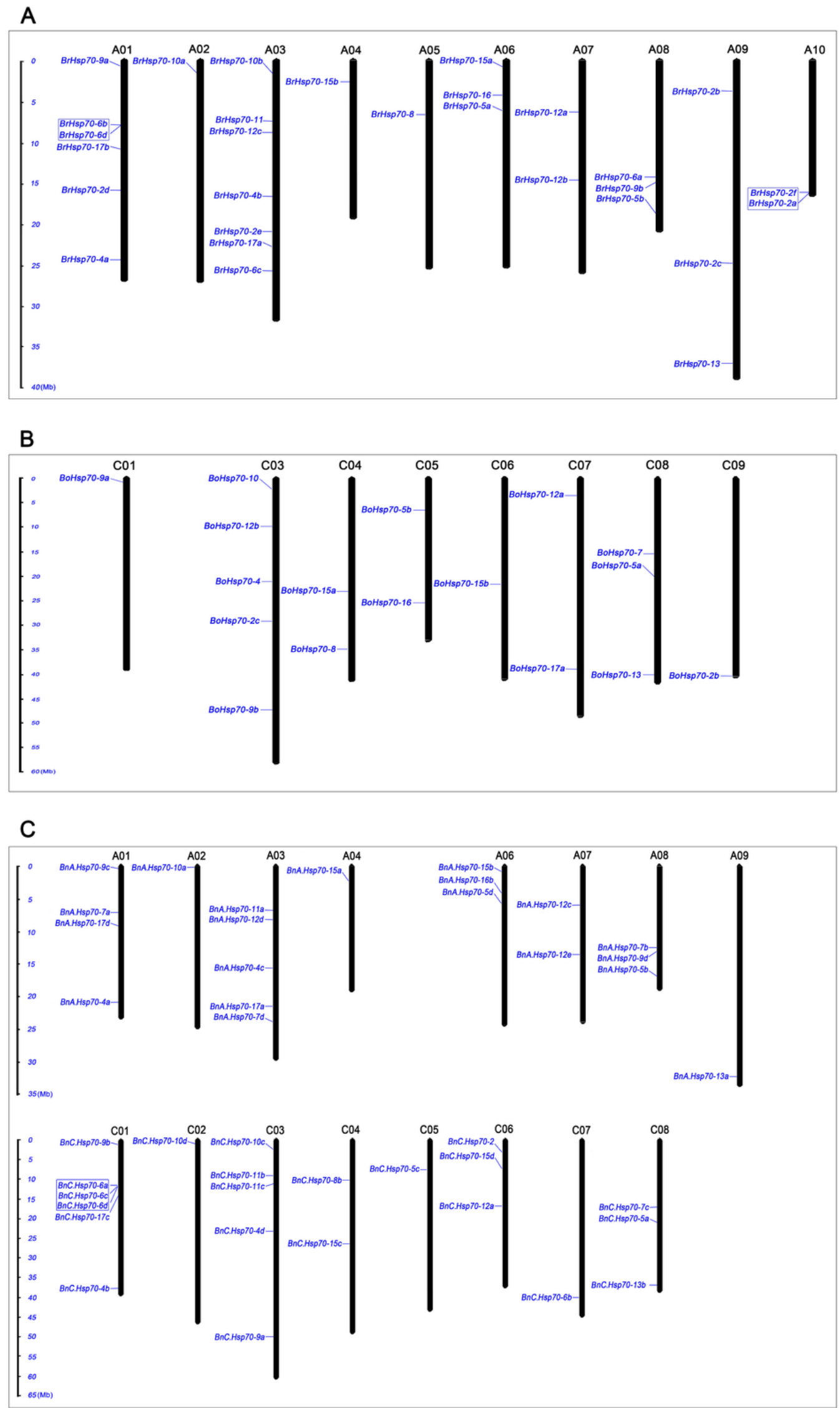
Figure 4

Genome-wide synteny analysis for $H s p 70$ genes among $B$. napus, $B$. rapa and $B$. oleracea.

(A) Synteny analysis of $H s p 70$ genes on $A_{n}$ and $C_{n}$ subgenome in B. napus. (B) Synteny analysis of $H s p 70$ genes between $A_{n}$ subgenome of B. napus and B. rapa. (C) Synteny analysis of $H s p 70$ genes between $C_{n}$ subgenome of $B$. napus and $B$. oleracea. Inside the circos, brown lines linked the syntenic orthologs and blue lines linked the syntenic paralogs.
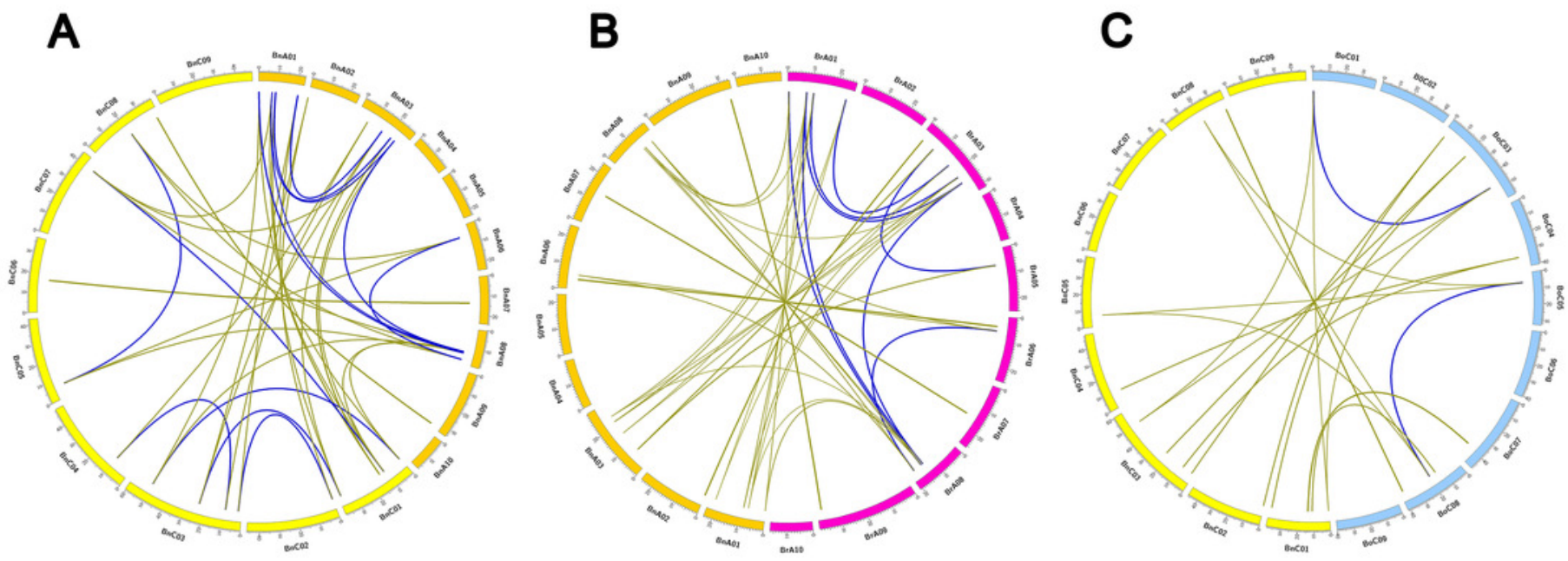


\section{Figure 5}

Expression patterns of $\mathrm{Hsp70}$ genes in four tissues (stem, leaf, flower and silique).

(A) Expression levels of $28 \mathrm{Hsp70}$ genes in different tissues of $B$. rapa. (B) Expression levels of $20 \mathrm{Hsp70}$ genes in different tissues of B. oleracea. (C) Expression levels of $46 \mathrm{Hsp70}$ genes in different tissues of $B$. napus. The log-transformed values of the expression trends of $H s p 70$ genes were used for hierarchical cluster analysis (original data shown in Table S9). BnC.Hsp70-6d and BrHsp70-6d were not shown because their relevant gene expression data were not detected. The color scale in the bottom represented expression levels with high transcript abundances (yellow) or low transcript abundances (blue). 


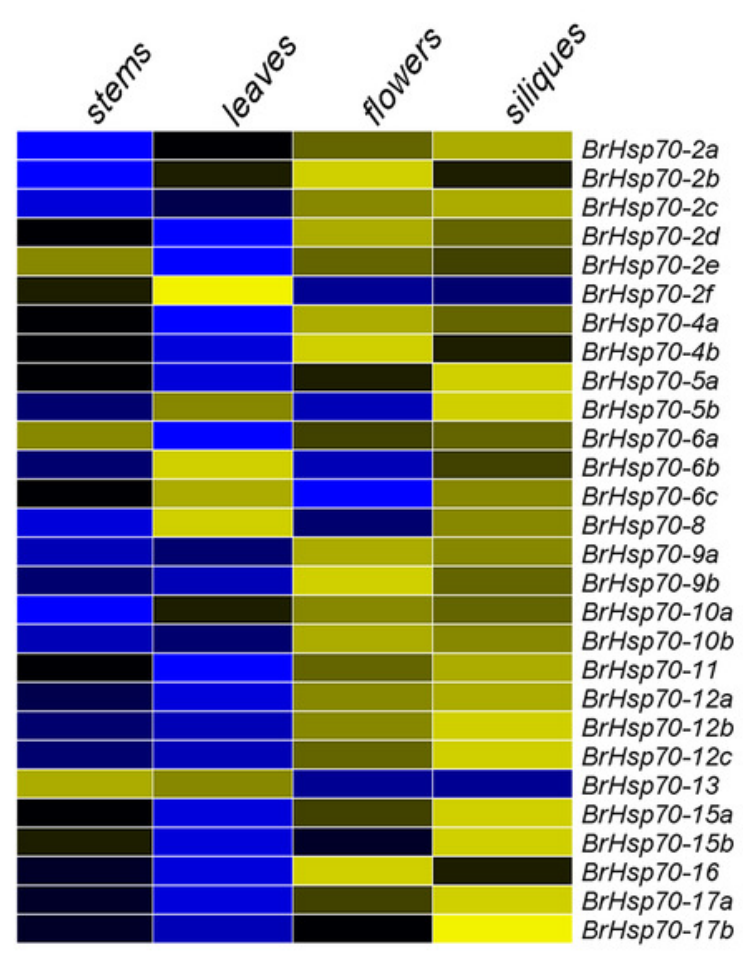

A

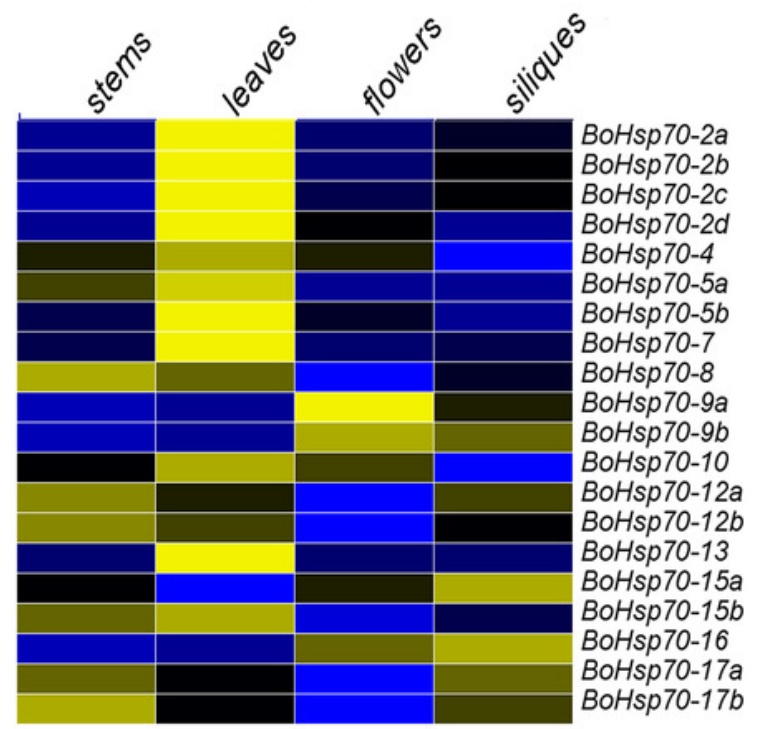

B
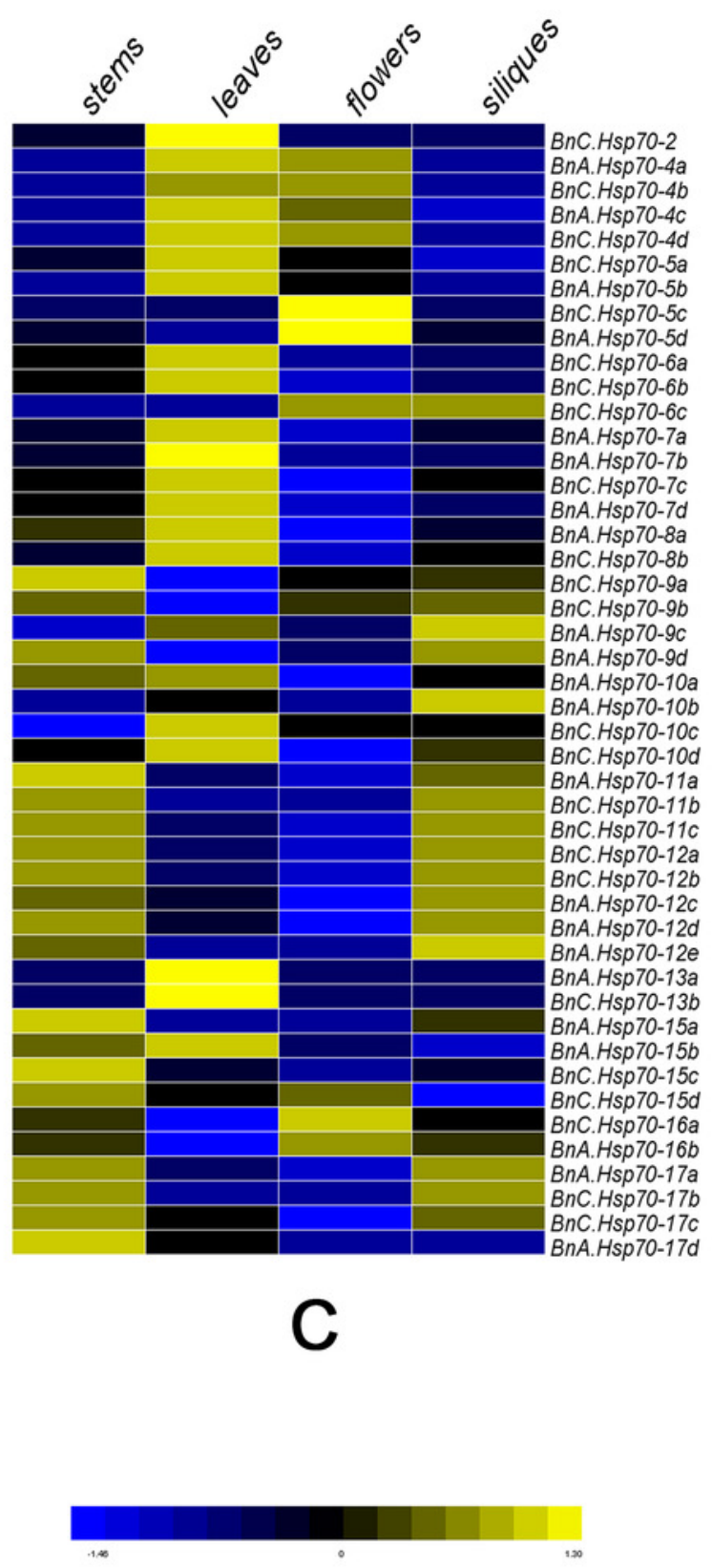


\section{Table $\mathbf{1}$ (on next page)}

The Hsp70 gene family information in Brassica napus (cv. Darmor-bzh).

All 47 BnHsp70 genes were identified using BLASTp program (BRAD;

http://Brassicadb.org/brad/) and HMM-based research (http://hmmer.org/). Details about $\mathrm{BnHsp70} \mathrm{gene} \mathrm{information} \mathrm{were} \mathrm{displayed.}$ 
Table 1 The Hsp70 gene family information in Brassica napus

\begin{tabular}{|c|c|c|c|c|c|c|}
\hline \multirow{2}{*}{ Gene name } & \multirow{2}{*}{ Gene ID } & \multirow{2}{*}{ Chromosome } & \multicolumn{2}{|c|}{ Gene position } & \multirow{2}{*}{ Intron number } & \multirow{2}{*}{ Arabidopsis orthologue locus } \\
\hline & & & start & end & & \\
\hline BnC.Hsp 70-2 & BnaC06g01970D & $\mathrm{C} 06$ & 2740114 & 2742008 & 3 & $A T 5 G 02500$ \\
\hline BnA.Hsp $70-4 a$ & BnaA0lg $30490 D$ & A01 & 20924063 & 20926784 & 1 & AT3G12580 \\
\hline BnC.Hsp $70-4 b$ & BnaC01g38510D & $\mathrm{C} 01$ & 37542383 & 37544742 & 1 & AT3G12580 \\
\hline BnA.Hsp 70-4c & BnaA03g32320D & $\mathrm{A} 03$ & 15595155 & 15597674 & 1 & AT3G12580 \\
\hline BnC.Hsp70-4d & BnaC03g37680D & $\mathrm{C} 03$ & 23044377 & 23047457 & 1 & AT3G12580 \\
\hline BnC.Hsp 70-5a & BnaC08g16850D & $\mathrm{C} 08$ & 20685045 & 20687250 & 0 & $A T 1 G 16030$ \\
\hline BnA.Hsp $70-5 b$ & BnaA08g23680D & A08 & 16771839 & 16774100 & 0 & ATIG16030 \\
\hline BnC.Hsp70-5c & BnaC05g12240D & $\mathrm{C} 05$ & 7096804 & 7098541 & 0 & ATIG16030 \\
\hline BnA.Hsp 70-5d & BnaA06g10730D & A06 & 5644636 & 5646192 & 0 & $A T 1 G 16030$ \\
\hline BnC.Hsp70-6a & BnaC0lg16200D & $\mathrm{C} 01$ & 11153984 & 11157177 & 7 & $A T 4 G 24280$ \\
\hline BnC.Hsp70-6b & BnaC07g38890D & $\mathrm{C} 07$ & 40064163 & 40067444 & 7 & $A T 4 G 24280$ \\
\hline BnC.Hsp 70-6c & BnaC01g16210D & $\mathrm{C} 01$ & 11160781 & 11163748 & 8 & $A T 4 G 24280$ \\
\hline BnC.Hsp $70-6 d$ & BnaC01gl6230D & $\mathrm{C} 01$ & 11165715 & 11169700 & 8 & $A T 4 G 24280$ \\
\hline BnA.Hsp 70-7a & BnaA0lg13780D & A01 & 7016235 & 7022008 & 8 & AT5G49910 \\
\hline BnA.Hsp $70-7 b$ & BnaA08g14780D & A08 & 12392265 & 12395010 & 7 & AT5G49910 \\
\hline BnC.Hsp $70-7 c$ & BnaC08g11440D & $\mathrm{C} 08$ & 16837653 & 16840640 & 7 & AT5G49910 \\
\hline BnA.Hsp $70-7 d$ & BnaA03g46660D & $\mathrm{A} 03$ & 23955244 & 23958060 & 7 & AT5G49910 \\
\hline BnA.Hsp $70-8 a$ & BnaAnng32550D & Ann_random & 37160556 & 37163177 & 0 & AT2G32120 \\
\hline BnC.Hsp 70-8b & BnaC04g12620D & $\mathrm{C} 04$ & 9850675 & 9852366 & 0 & AT2G32120 \\
\hline BnC.Hsp70-9a & BnaC03g61170D & $\mathrm{C} 03$ & 50146745 & 50149558 & 4 & AT4G37910 \\
\hline BnC.Hsp $70-9 b$ & BnaC01g01110D & $\mathrm{C} 01$ & 481765 & 484468 & 4 & AT4G37910 \\
\hline BnA.Hsp $70-9 c$ & BnaA01g00190D & $\mathrm{A} 01$ & 66872 & 69292 & 4 & AT4G37910 \\
\hline BnA.Hsp 70-9d & BnaA08g15870D & A08 & 13148193 & 13150962 & 4 & AT4G37910 \\
\hline BnA.Hsp 70-10a & BnaA02g00030D & $\mathrm{A} 02$ & 14834 & 18467 & 5 & AT5G09590 \\
\hline BnA.Hsp 70-10b & BnaA03g55950D & A03_random & 489297 & 492462 & 4 & AT5G09590 \\
\hline BnC.Hsp $70-10 c$ & BnaC03g03860D & $\mathrm{C} 03$ & 1874440 & 1877474 & 4 & AT5G09590 \\
\hline BnC.Hsp 70-10d & BnaC02g00800D & $\mathrm{C} 02$ & 315889 & 320718 & 8 & AT5G09590 \\
\hline BnA.Hsp 70-11a & BnaA03g14210D & $\mathrm{A} 03$ & 6518376 & 6521390 & 6 & $A T 5 G 28540$ \\
\hline BnC.Hsp 70-11b & BnaC03g17190D & $\mathrm{C} 03$ & 8771430 & 8774421 & 6 & AT5G28540 \\
\hline BnC.Hsp 70-11c & BnaC03g20620D & $\mathrm{C} 03$ & 10938331 & 10941303 & 5 & $A T 5 G 28540$ \\
\hline BnC.Hsp $70-12 a$ & BnaC06g13860D & $\mathrm{C} 06$ & 16719969 & 16728133 & 5 & AT5G42020 \\
\hline BnC.Hsp $70-12 b$ & BnaC07g48050D & C07_random & 418733 & 421268 & 5 & AT5G42020 \\
\hline BnA.Hsp $70-12 c$ & BnaA07g05610D & A07 & 5907236 & 5909961 & 5 & AT5G42020 \\
\hline BnA.Hsp 70-12d & BnaA03g17100D & $\mathrm{A} 03$ & 8025655 & 8028557 & 5 & AT5G42020 \\
\hline BnA.Hsp $70-12 e$ & BnaA07g15650D & A07 & 13485784 & 13488485 & 7 & AT5G42020 \\
\hline BnA.Hsp $70-13 a$ & BnaA09g48560D & A09 & 32511931 & 32514629 & 5 & AT1G09080 \\
\hline
\end{tabular}




\begin{tabular}{|llccccc|} 
BnC.Hsp70-13b & BnaC08g42820D & C08 & 36848273 & 36850808 & 5 & $A T 1 G 09080$ \\
BnA.Hsp70-15a & BnaA04g03290D & A04 & 2140854 & 2144541 & 8 & $A T 1 G 79930$ \\
BnA.Hsp70-15b & BnaA06g00870D & A06 & 609868 & 615315 & 10 & $A T 1 G 79930$ \\
BnC.Hsp70-15c & BnaC04g25190D & C04 & 26110817 & 26117673 & 10 & $A T 1 G 79930$ \\
BnC.Hsp70-15d & BnaC06g06400D & C06 & 6884609 & 6890728 & 14 & $A T 1 G 79930$ \\
BnC.Hsp70-16a & BnaCnng18070D & Cnn_random & 16871440 & 16875094 & 8 & AT1G11660 \\
BnA.Hsp70-16b & BnaA06g07260D & A06 & 3868981 & 3872471 & 8 & AT1G11660 \\
BnA.Hsp70-17a & BnaA03g42810D & A03 & 21484934 & 21489471 & 13 & AT4G16660 \\
BnC.Hsp70-17b & BnaC07g50110D & C07_random & 2420784 & 2425332 & 13 & AT4G16660 \\
BnC.Hsp70-17c & BnaC01g19960D & C01 & 13882083 & 13886038 & 13 & AT4G16660 \\
BnA.Hsp70-17d & BnaA01g17140D & A01 & 9007657 & 9011549 & 13 & $A T 4 G 16660$ \\
\hline
\end{tabular}

